\title{
Formación de precios en la agricultura de alimentación ${ }^{*}$
}

Fidel Enrique Majano Trejo

Ada Erlyn Méndez Narváez

\section{Introducción}

Tradicionalmente se ha tendido a creer que las variaciones en los precios de los productos agricolas de alimentación obedecen exclusivamente a los comportamientos directos de su oferta y demanda internas. En realidad, estas variaciones son el resultado de la interacción de una diversidad de factores, unos que responden a la producción y otros al mercado.

La investigación sobre la formación de precios de los granos básicos se justifica no sólo por las variaciones observables de los mismos en el mercado; sino porque de estos movimientos depende en gran medida la capacidad adquisitiva de los sectores de más bajos ingresos de la población. Por un lado, la tendencia alcista de los precios de los granos da como resultado una disminución de la capacidad adquisitiva de los consumidores finales; por otro, su forma de determinación y su estructura de comercialización contribuyen al deterioro de las condiciones económicas de los pequeños productores agrícolas.

En este sentido, el presente estudio pretende conocer cuáles son los mecanismos responsables de los movimientos de los precios de estos productos; buscando responder para ello a las siguientes interrogantes:

- ¿Cuáles son y cómo se determinan los componentes del precio, de acuerdo a la lógica del productor directo?

- ¿Cuáles son los mecanismos del mercado que intervienen en la

- El presente artículo es una sintesis de los principales aspectos de una investigación realizada como trabajo de graduación, bajo la asesorla de Roberto Rivera Campos. 
fijación del precio y en sus variaciones?

- ¿A través de qué vias, los mecanismos de formación de los precios contribuyen a una redistribución regresiva del ingreso?

- ¿Qué papel juegan las regulaciones estatales en la dinámica de los precios?

Con el fin de establecer una respuesta, el trabajo ha sido estructurado en tres apartados.

El primero se refiere a los resultados obtenidos de la investigación de campo al productor y a los intermediarios.

En el segundo apartado se examinan las implicaciones del sistema de formación de precios de los granos básicos; asimismo, se estudian los factores que acentúan o atenúan la forma en que tales precios son determinados.

Finalmente, se presentan las conclusiones más relevantes y algunas recomendaciones tendientes a dar solución a los problemas detectados.

I. Factores que intervienen en la formaclón de los preclos de los productos agrícolas de allmentaclón: presentaclón de resultados

\subsection{Delimitación y metodología}

El presente estudio centra la atención en los pequeños productores agrícolas, dado que, según el Tercer Censo Nacional Agropecuario (1971), del total de la producción de maíz, frijol y arroz, las explotaciones comprendidas entre menos de $1 \mathrm{Ha}$. hasta 9.9 Has. aseguraban el $72 \%$, $77 \%$ y $46 \%$ de la producción nacional respectivamente.

Si bien la atención fue enfocada sobre los pequefios productores, se hizo necesario considerar, además, como un caso especial a los medianos y grandes productores de arroz, debido a que tal como revela el documento antes mencionado, el $51 \%$ del total de la producción nacional era generado en este tipo de explotaciones.

Respecto al área donde se realizaron las encuestas, ésta comprende los departamentos de Santa Ana, Sonsonate, La Libertad, Chalatenango y La Unión.

Dado que se trata de evidenciar empíricamente los mecanismos de formación de los precios de los productores agrícolas de alimentación, la recolección de datos se llevó a cabo mediante la realización de 71 encuestas (número correspondiente a una muestra significativa), basadas en los objetivos e hipótesis de trabajo.

Hay que señalar que se está consciente de las limitaciones intrin- 
secas a toda investigación basada en encuestas y entrevistas; ante todo, en los aspectos de la precisión de las respuestas obtenidas cuando se abordan de manera inesperada a los individuos y en la restringida percepción global del fenómeno que podría generarse.

A pesar de eso, los resultados obtenidos permiten afirmar que la información recabada refleja adecuadamente las caracteristicas esenciales del fenómeno estudiado.

\subsection{Estructura de costos}

La estructura de costos de los granos básicos está compues4a, en términos generales, por cuatro rubros, a saber, insumos, mano de obra, renta y maquinaria.

La participación que cada factor tenga en los costos totales dependerá no sólo del producto, sino también de la forma en que su proceso de producción es desarrollado.

Según datos obtenidos, el $65.12 \%$ de los productores de maiz y frijol afirmó gastar más en insumos; el mayor gasto en que incurren es en concepto de abonos y fertilizantes, lo que no es raro si se considera la baja fertilidad de las tierras utilizadas.

\section{CUADRO N 1}

Pequefos productores: particlpaclón de los factores dentro de los costos totales por producto (\%)

\begin{tabular}{|l|c|c|}
\hline PRODUCTO & MAIZ Y FRIJOL & ARROZ \\
\hline FACTORES & 65.12 & 60.0 \\
\hline $\begin{array}{l}\text { INSUMOS } \\
\text { OBNO DE }\end{array}$ & 27.91 & 30.0 \\
\hline $\begin{array}{l}\text { INSUMOS } \\
\text { YMANO DE OBRA }\end{array}$ & 2.33 & 0.0 \\
\hline $\begin{array}{l}\text { RENTA } \\
\text { MAQUINARIA }\end{array}$ & 4.65 & 5.0 \\
\hline $\begin{array}{l}\text { TOTAL \% } \\
\text { (\%) }\end{array}$ & 0.0 & 5.0 \\
\hline
\end{tabular}

Fuente Elaboración propia en base a encuesta. 


\section{CUADRO N²}

Productores de granos: particlpación de los factores dentro de los costos totales por producto (\%)

\begin{tabular}{|l|c|}
\hline \multicolumn{1}{|c|}{ PRODUCTORES } & $\begin{array}{c}\text { \% DE } \\
\text { FACTORES }\end{array}$ \\
\hline PRODUCTORES \\
\hline $\begin{array}{l}\text { MANO DE } \\
\text { OBRA }\end{array}$ & 63.38 \\
\hline $\begin{array}{l}\text { INSUMOS } \\
\text { YMANO DE OBRA }\end{array}$ & 28.17 \\
\hline RENTA & 1.41 \\
\hline MAQUINARIA & 4.23 \\
\hline $\begin{array}{l}\text { TOTAL \% } \\
\text { (\%) }\end{array}$ & 2.82 \\
\hline
\end{tabular}

Fuente IBID.

Aunque se gaste relativamente más en lograr cierto grado de productividad de la tierra por este medio, no significa que no haya una considerable participación de la fuerza de trabajo en el proceso de producción. Lo que sucede es que esto no se refleja en su justa dimensión en los costos, por el hecho que suele usarse fuerza de trabajo familiar, cuya reproducción no es contabilizada por estos productores como parte de los costos de producción. Asi, del total de productores de maiz y frijol, el $74.4 \%$ manifestó recibir ayuda permanente de miembros de su familia, mientras que la contratación de jornaleros es temporal y reducida en número, limitándose a los momentos "crílicos" del proceso de producción. Además, el $60.47 \%$ de los productores que reciben ayuda familiar no incluye en sus costos este tipo de trabajo.

La explicación de esto se encuentra en que debido a su precariedad económica les es imposible contratar jornaleros de manera permanente, de tal forma que deben recurrir al uso de fuerza de trabajo familiar, lo que no se traduce en costos, ya que es una parte de la producción la que sirve como medio de vida y, por tanto, como medio de reproducción de la fuerza de trabajo familiar.

En el caso del arroz, también son los insumos los que tienen mayor participación en los costos totales, siguiendo en orden los incurridos en mano de obra. El $60 \%$ de los productores de arroz manifestó gastar más en insumos. (Cfr. Cuadro N²1). 


\section{CUADRO №3}

Pequefios productores que reclben ayuda famlllar, que contratan jornaleros y que utllizan maquinarla (\%)

\begin{tabular}{|l|l|l|l|c|c|}
\hline \multicolumn{2}{|c|}{ RESPUESTAS } & SI & No & $\begin{array}{c}\text { Cesos } \\
\text { especlales }\end{array}$ & $\begin{array}{c}\text { Total } \% \\
(\mathbf{n})\end{array}$ \\
\hline $\begin{array}{l}\text { PREGUNTAS } \\
\text { ¿amente sus fami- } \\
\text { liares en la produc- } \\
\text { ción? }\end{array}$ & M Y F & 74.42 & 25.58 & - & $\begin{array}{c}100.0 \\
(43)\end{array}$ \\
\cline { 2 - 6 } & ARROZ & 70.0 & 30.0 & - & $\begin{array}{c}100.0 \\
(20)\end{array}$ \\
\hline $\begin{array}{l}\text { ¿Incluye el trabajo } \\
\text { familiar en sus cos- } \\
\text { tos? }\end{array}$ & M Y F & 13.95 & 60.47 & 25.58 a) & $\begin{array}{c}100.0 \\
(43)\end{array}$ \\
\cline { 2 - 6 } & ARROZ & 20.0 & 50.0 & 30.0 a) & $\begin{array}{c}100.0 \\
(20)\end{array}$ \\
\hline \multirow{2}{*}{$\begin{array}{l}\text { Contrata } \\
\text { ¿Jornaleros? }\end{array}$} & M Y F & 83.72 & 16.28 & - & $\begin{array}{c}100.0 \\
(43)\end{array}$ \\
\cline { 2 - 6 } & ARROZ & 100.0 & 0.0 & - & $\begin{array}{c}100.0 \\
(20)\end{array}$ \\
\hline Utiliza & M Y F & 0.0 & 100.0 & - & $\begin{array}{c}100.0 \\
(43)\end{array}$ \\
\cline { 2 - 6 } & ARROZ & 56.25 & 43.75 & - & $\begin{array}{c}100.0 \mathrm{~b}) \\
(16)\end{array}$ \\
\hline \multirow{2}{*}{ ¿Maquinaria? } & & & & & \\
\hline
\end{tabular}

Fuente: IBID.

a) Productores que trabajan solos, por lo que se excluyeron de la pregunta.

b) Excluye a 4 productores para los cuales no se dispone de esta información.

Ahora bien, en la producción de arroz la participación de la mano de obra en la estructura de costos no depende tanto del uso de fuerza de trabajo familiar como de la utilización de maquinaria. Los resultados muestran que el $100 \%$ de los productores de arroz encuestados contratan jornaleros; es decir, no hay en la muestra ningún productor de éstos a quien la ayuda de los miembros de su familia le sea suficiente. Esto debido a que la recolección de este grano exige un alto número de jornaleros (en periodos de siembra y recolección), a diferencia del maiz y del frijol. De alli que la proporción en que la fuerza de trabajo participe en la estructura de costos dependerá del uso de maquinaria. 
De esta manera, si la siembra es realizada con maquinaria, el número de contratados por manzana se reduce. Este efecto es más notable durante la recolección, ya que si ésta se hace por medio de una máquina, la producción de $1 \mathrm{mz}$. es recolectada en un dia, trabajo que implicaría el empleo de más días/hombre.

En términos globales, se puede afirmar que son los insumos los que tienen mayor peso dentro de la estructura de costos de los granos básicos, hecho que puede ser explicado conjuntamente por el alto precio de los mismos $y$, en el caso concreto del maiz y del frijol, adicionalmente por la baja fertilidad de las parcelas.

El segundo lugar lo ocupa el costo de la mano de obra. De acuerdo a la muestra, sólo el $28.17 \%$ manifestó gastar más en este rubro. (Cfr. Cuadro $\mathrm{N}^{2}$ 2).

Evidentemente, la renta no es significativa en la estructura de costos de los productores arrendatarios, quienes representan un $34.92 \%$ del total de pequeños productores encuestados. Esto puede explicarse porque el costo de arrendamiento por manzana es relativamente bajo y se ve opacado ante el costo de los demás factores.

Ahora bien, que el agricultor cubra o no sus costos totales y que, por tanto, éstos jueguen un papel determinante en el establecimiento y en las variaciones de los precios, depende considerablemente de los mecanismos y canales de comercialización.

\subsection{Agentes de la comerciallzación}

La comercialización de maíz, frijol y arroz es realizada, en la mayoría de los casos, a través de intermediarios: el $78.6 \%$ de los pequeños productores encuestados vende exclusivamente a estos agentes.

Al respecto, la investigación revela una serie de problemas que derivan de sus condiciones económicas y que los obligan a vender de inmediato la cosecha; son problemas tales como la incapacidad de almacenamiento la falta de transporte y la necesidad de efectivo. Precisamente y en consecuencia, son éstas las mismas razones por las que venden a los intermediarios.

Asimismo el estudio demuestra que la generalidad de los agricultores no vende al IRA porque éste no paga inmediatamente o porque no les recibe la cosecha.

Puede deducirse que el productor, frente a las trabas del IRA se ve obligado, ante la necesidad de obtener dinero de inmediato y por su falta de transporte y de almacenamiento, a vender a los intermediarios comerciales, lo que no les significa pago de transporte ni el riesgo de que la 
Pequefiosproductores:participaclóndelIRAy losintermedlarlosen la comerclallzaclón (\%)

\begin{tabular}{|l|c|}
\hline \multicolumn{1}{|c|}{ PREGUNTA } & $\begin{array}{c}\text { iA QUIEN } \\
\text { VENDE? }\end{array}$ \\
\hline IRA & 3.57 \\
\hline INTERMEDIARIO & 78.57 \\
\hline CONSUMIDOR & 8.93 \\
\hline $\begin{array}{l}\text { IRA } \\
\text { INTERMEDIARIO }\end{array}$ & 3.57 \\
\hline $\begin{array}{l}\text { INTERMEDIARIO } \\
\text { CONSUMIDOR }\end{array}$ & 3.57 \\
\hline $\begin{array}{l}\text { IRA, INTERMEDIARIO } \\
\text { CONSUMIDOR }\end{array}$ & 1.79 \\
\hline $\begin{array}{l}\text { TOTAL \% } \\
\text { (n) }\end{array}$ & $\begin{array}{c}100.0 \\
(56)\end{array}$ \\
\hline
\end{tabular}

Fuenle IBID.
Pequenos productores: razones de la venta Inmedlata (\%)

\begin{tabular}{|l|c|}
\hline \multicolumn{1}{|c|}{ PREGUNTA } & $\begin{array}{c}\text { ¿PORQUE } \\
\text { VENDE DE } \\
\text { INMEDIATO? }\end{array}$ \\
\hline $\begin{array}{l}\text { INCAPACIDAD DE (A) } \\
\text { ALMACENAMIENTO }\end{array}$ & 23.21 \\
\hline $\begin{array}{l}\text { FALTA DE } \\
\text { TRANSPORTE (B) }\end{array}$ & 3.57 \\
\hline $\begin{array}{l}\text { NECESIDAD DE } \\
\text { EFECTIVO (C) }\end{array}$ & 21.43 \\
\hline $\begin{array}{l}\text { (A) Y (C) } \\
\text { COMBINADAS }\end{array}$ & 16.07 \\
\hline $\begin{array}{l}\text { (A) Y (B) } \\
\text { COMBINADAS }\end{array}$ & 7.14 \\
\hline $\begin{array}{l}\text { NO VENDE DE } \\
\text { INMEDIATO }\end{array}$ & 28.57 \\
\hline $\begin{array}{l}\text { TOTAL \% } \\
\text { (n) }\end{array}$ & 100.0 \\
\hline
\end{tabular}

Fuente IBID.

producción no les sea recibida y les permite obtener inmediatamente el dinero de la venta.

\subsection{Papel de los agentes de la comercialización en la fijación del precio}

Respecto a la relación entre los productores y los intermediarios, las decisiones sobre el precio al que se valúa la producción destinada al mercado son tomadas, en el $75 \%$ de los casos, por los intermediarios. Esto se debe a que las condiciones económicas del pequefio productor no le permiten el poder de negociación suticiente como para fijar el precio al que venderá.

Cuando la producción es vendida al IRA, ocurre una situación semejante; aqui el agricultor debe vender a los precios de garantia impuestos por esta institución y bajo las normas de calidad que le exige. 


\section{CUADRO N² 6}

Pequeños productores: causas de la relación comerclal productores-agentes (\%)

\begin{tabular}{|c|c|c|c|c|c|c|}
\hline $\begin{array}{l}\text { AGENTES } \\
\text { Porqué } \\
\text { vénde a } \\
\text { ese agente? }\end{array}$ & $\begin{array}{l}\text { (a) } \\
\text { Inter- } \\
\text { med. }\end{array}$ & $\begin{array}{l}\text { (b) } \\
\text { IRA }\end{array}$ & $\begin{array}{c}\text { (c) } \\
\text { Conau- } \\
\text { mid. }\end{array}$ & (a) y (b) & (e) y (c) & $\underset{\text { (c) }}{(a),(b)}$ \\
\hline $\begin{array}{l}\text { Paga mejor } \\
\text { precio }\end{array}$ & 7.14 & (3.57) & - & 1.79 & - & - \\
\hline $\begin{array}{l}\text { Paga de } \\
\text { inmediato }\end{array}$ & 12.50 & - & - & - & - & - \\
\hline $\begin{array}{l}\text { IfA no recibió } \\
\text { toda o parte } \\
\text { de la cosecha }\end{array}$ & 8.93 & - & - & 1.79 & 1.79 & - \\
\hline $\begin{array}{l}\text { Sólo élle } \\
\text { compra }\end{array}$ & 3.57 & - & 1.79 & - & - & - \\
\hline Por costumbre & 12.50 & 一 & - & 一 & - & - \\
\hline $\begin{array}{l}\text { Necesidad de } \\
\text { efectivo }\end{array}$ & 8.93 & - & - & - & - & 1.79 \\
\hline Coseche poco & 一 & - & 3.57 & - & 一 & 一 \\
\hline $\begin{array}{l}\text { Normas } \\
\text { flexibles de } \\
\text { calidad }\end{array}$ & 3.57 & - & - & - & - & - \\
\hline $\begin{array}{l}\text { Falta de } \\
\text { transporte }\end{array}$ & 21.43 & - & - & - & 1.79 & 一 \\
\hline $\begin{array}{l}\text { Porque le es } \\
\text { más rentable }\end{array}$ & - & - & 3.57 & 一 & - & - \\
\hline $\begin{array}{l}\text { TOTAL } \% \\
\text { (n) }\end{array}$ & \multicolumn{6}{|c|}{$\begin{array}{c}100.0 \\
(56)\end{array}$} \\
\hline
\end{tabular}

Fuente: IBID

Es necesario recalcar que el problema no estriba simplemente en el hecho de que no sean ellos quienes deciden el precio en sus relaciones con los agentes mencionados; sino en que ese precio, con frecuencia, no cubre los costos de producción considerados por el agricultor. Este fenómeno se observó para el $77.8 \%$ de productores de maiz y frijol. Por 
Pequenos productores: causas de la no relación comerclal productores-IRA (\%)

\begin{tabular}{|l|c|}
\hline ¿POR QUE NO VENDE A OTRO COMPRADOR? & $\begin{array}{c}\text { PORCENTANE } \\
\text { DE } \\
\text { PRODUCTORES }\end{array}$ \\
\hline $\begin{array}{l}\text { IRA PAGA BARATO Y PRESENTA MUCHAS } \\
\text { DIFICULTADES }\end{array}$ & 5.36 \\
\hline LEJANIA DEL MERCADO & 10.71 \\
\hline NO VENDE AL IRA POROUE BUSCA MEJOR PRECIO & 7.14 \\
\hline EN EL IRA HAY MUCHA DIFICULTAD Y PAPELEO & 16.07 \\
\hline IRA NO RECIBIO TODA O PARTE DE LA COSECHA & 14.29 \\
\hline IRA NO PAGA DE INMEDIATO & 21.43 \\
\hline CERCANIA DEL MERCADO & 3.57 \\
\hline INTERMEDIARIO PAGA MENOS QUE IRA & 1.79 \\
\hline $\begin{array}{l}\text { IRA NO CUENTA CON RECIBIDERO CERCA Y NO LLEGA } \\
\text { A COMPRARLES AL LUGAR }\end{array}$ & 3.57 \\
\hline CONFIA MAS EN INTERMEDIARIOS QUE EN IRA & 8.93 \\
\hline $\begin{array}{l}\text { IRA: NORMAS RIGIDAS DE CALIDAD Y SOLO RECIBE } \\
\text { A DEUDORES DEL B.F.A. }\end{array}$ & 3.57 \\
\hline NO LE ES RENTABLE VENDER AL IRA & 3.57 \\
\hline TOTAL \% (n) & 100.0 \\
\hline FUONO: & \\
\hline
\end{tabular}

Fuente: IBID

el contrario, el $85 \%$ de los pequeños productores de arroz dijo cubrir sus costos al precio fijado.

No hay duda que el arroz es un producto rentable si se compara con el maiz y el frijol, a tal grado que cuando los agricultores alternan la siembra de sus cultivos, los ingresos obtenidos de la comercialización del arroz les permiten compensar en alguna medida las pérdidas del cultivo alter- 
CUADRO NN8

Pequefios productores: decislón del preclo de venta (\%)

\begin{tabular}{|l|c|c|}
\hline PREGUNTA & $\begin{array}{c}\text { iQUIEN DECIDE } \\
\text { EL PRECIO } \\
\text { DE VENTA? }\end{array}$ & $\begin{array}{c}\text { TOTAL \% } \\
\text { (n) }\end{array}$ \\
\hline INTERMEDIARIO & 75.0 & \\
\cline { 1 - 2 } IRA & 5.36 & $\begin{array}{c}100.0 \\
(56)\end{array}$ \\
\cline { 1 - 2 } PRODUCTOR & 7.14 & \\
\hline $\begin{array}{l}\text { INTERMEDIARIO } \\
\text { - IRA }\end{array}$ & 12.50 & \\
\hline
\end{tabular}

Fuente: IBID

CUADRO N 9

Pequenos productores: porcentaje que cubre sus costos

\begin{tabular}{|c|c|c|c|}
\hline \multicolumn{2}{|c|}{ ALTERNATIVAS } & $\begin{array}{c}\text { CUBRE SUS } \\
\text { COSTOS EL PRECIO } \\
\text { PAGADO }\end{array}$ & $\begin{array}{c}\text { TOTAL } \% \\
\text { (n) }\end{array}$ \\
\hline \multirow{2}{*}{ S1 } & $\stackrel{M}{F} Y$ & 22.22 & $\begin{array}{c}100.0 \\
(36)\end{array}$ \\
\hline & ARROZ & 85.0 & $\begin{array}{c}100.0 \\
(20)\end{array}$ \\
\hline \multirow{2}{*}{ NO } & ${ }_{F}^{M} Y$ & 77.78 & $\begin{array}{c}100.0 \\
(36)\end{array}$ \\
\hline & ARROZ & 15.0 & $\begin{array}{c}100.0 \\
(20)\end{array}$ \\
\hline
\end{tabular}

Fuente: IBID

nativo y financiar su producción en el siguiente periodo.

En la fijación del precio, si bien los costos juegan un papel importante, son los agentes del mercado y la situación del mismo los mecanismos determinantes a la hora de establecer el precio de compra al productor.

En consecuencia, que el precio resultante cubra el costo de producción dependerá basicamente de dos factores: el poder de ne- 
gociación del agricultor, y la situación del mercado, en términos de oferta y demanda.

\subsection{Los canales de comerclallzación}

Dentro del mercado existen, por el lado de la oferta, básicamente tres agentes, a saber: el transportista, mayorista, y el minorista o detallista (de carácter privado), el productor directo y el IRA (de carácter oficial): por el lado de la demanda, el consumidor final. Cada uno de ellos presenta determinadas condiciones que les permiten tener diferentes niveles de poder de negociación respecto al establecimiento del precio al que compran y venden el producto. Ello se expresa en los distintos grados de influencia o control que sobre la oferta y los precios tienen cada uno de ellos.

PRODUCTOR DIRECTO: puede afirmarse que la capacidad del productor para especular con la cosecha y los precios es nula $y$, a nivel global del mercado, su grado de influencia sobre la oferta como mecanismo para manipular los precios es prácticamente despreciable (ya que ofrece en el mercado una pequeña parte de la producción total)

TRANSPORTISTA: este goza de un mayor poder de negociación que el productor directo en relación al precio de compra de la producción; tiene una insignificante capacidad de especular con la producción que capta; presenta un reducido poder de negociación del precio de venta con respecto al mayorista. Por último, su grado de influencia sobre la oferta global es mínimo y sobre los precios es nulo (es un pequefio oferente entre muchos y, por tanto, un tomador de precios).

MAYORISTA: este agente ostenta un fuerte poder de negociación con el cual es capaz de incidir a su favor, tanto sobre el precio de compra como sobre el de venta, en su relación con el transportista, con el productor directo y con el minorista o, con el consumidor final respectivamente; principalmente por su capacidad económica y de almacenamiento, asi como por el considerable volumen de producto que logra retener. De alli que la capacidad de especular con el precio de los granos está concentrada en estos agentes $y$, en este sentido, su grado de influencia sobre la oferta y los precios es alto, siendo los que mayor dominio tienen sobre el mercado.

IRA: A nivel global del mercado esta institución ejerce una limitada influencia sobre la oferta y los precios, la cual se restringe básicamente a la parte del mercado que controla y en donde rigen sus precios, estando el resto del mercado bajo el control de los intermediarios (principalmente los mayoristas), bajo condiciones en que los precios de éstos no son influidos significativamente por los precios del IRA. 
MINORISTA: este agente no tiene influencia sobre el mercado y los precios (es un pequeno comprador y vendedor entre muchos).

CONSUMIDOR: éste es esencialmente un tomador de precios dentro del mercado, a nivel individual; pero determina en conjunto los movimientos de la demanda total, y por tanto, incide sobre el precio.

En relación al abastecimiento del mercado, los medios empleados en el caso del maiz y del trijol son muy similares, por lo que pueden ser representados en un mismo esquema. (Cfr. esquema № 1).

El flujo regular que predomina en estos productos parte del pequefio productor que vende su producción al transportista, quien la traslada a los centros urbanos en donde la vende al mayorista y éste a su vez al minorista, que finalmente la lleva a manos del consumidor.

Existen, además, otras formas de distribución que no son regulares, sino más bien ocasionales y que prevalecen menos dentro del mercado. Algunos transportistas pueden vender al IRA o al minorista, e incluso al consumidor. También el mayorista, en algunos casos, compra la cosecha directamente al productor y la vende, además del minorista, al consumidor. Finalmente, el productor que posee transporte puede comerciar personalmente con el minorista y consumidor. Por su parte, el IRA normalmente compra al productor directo y distribuye los productos al consumidor por medio de agencias propias.

Para el arroz, la corriente de abastecimiento al mercado es distinta. (Cfr. Esquema $N^{2} 2$ ). El flujo normal que predomina en este producto parte del productor que vende en granza al mayorista y al transportista; el primero lleva al molino de arroz la producción, donde la desgranza para luego venderla al detallista y de manera irregular también al consumidor. Con respecto al transportista, este la conduce al molino, donde se la compra el mayorista; aisladamente el IRA también puede comprarle al primero.

En algunos casos, el productor lleva personalmente el producto al molino, donde lo vende al mayorista, aunque éstos son los menos. Por último, el IRA regularmente compra al productor directo y lo lleva al molino por su cuenta, para luego distribuirlo por medio de sus agencias al consumidor.

\subsection{Factores naturales}

Dentro de los factores naturales que influyen sobre las condiciones objetivas del proceso de producción agrícola se encuentra la baja fertilidad que poseen las tierras dedicadas al cultivo de granos básicos, sobre la cual poco pueden hacer los productores, debido a sus condiciones de pobreza. 


\section{Esquema No 1 \\ Maiz y frljol: canales de distribuclón}

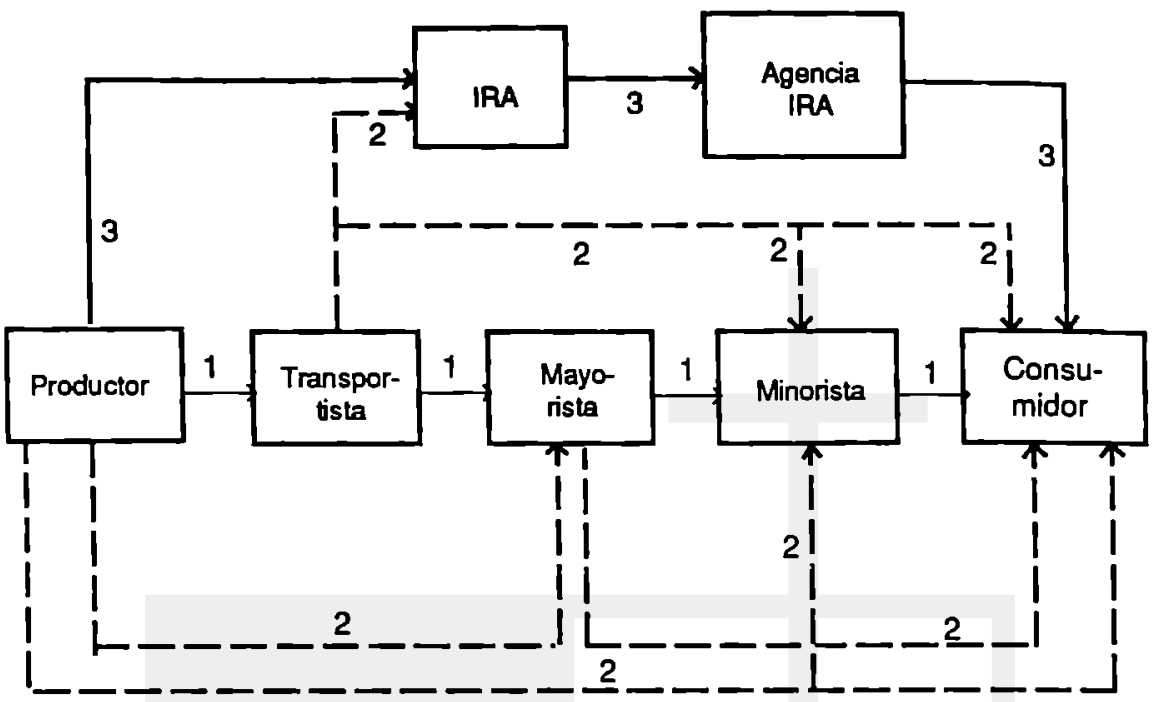

Fuente: Elaboración propia en base a investigación de campo.

FLUJO 1: Forma predominante de abastecimiento del mercado.

FLUJO 2: Forma ocasional de abastecimiento del mercado

FLUJO 3: Forma de abastecimiento del mercado a través del IRA.

Otro elemento tan importante como el anterior lo contituye el factor climatológico, pues ejerce una influencia determinante sobre las decisiones de producción de los agricultores.

De un total de 71 productores, el $87.32 \%$ son afectados en su proceso de producción por las condiciones climáticas.

CUADRO № 10

Pequenos y grandes productores Influencia de la sequia (\%)

\begin{tabular}{|c|c|c|}
\hline INFLUENCIA & $\begin{array}{c}\text { AFECTA } \\
\text { LA SEQUIA }\end{array}$ & $\begin{array}{c}\text { TOTAL \% } \\
\text { (N) }\end{array}$ \\
\hline ALTERNATIVA & 67.32 & $\begin{array}{c}100.0 \\
(71)\end{array}$ \\
\hline SI AFECTA & $12.68^{*}$ & \\
\hline
\end{tabular}

Fuente: IBID.

- Productores de arroz que tienen sistema de riego. 


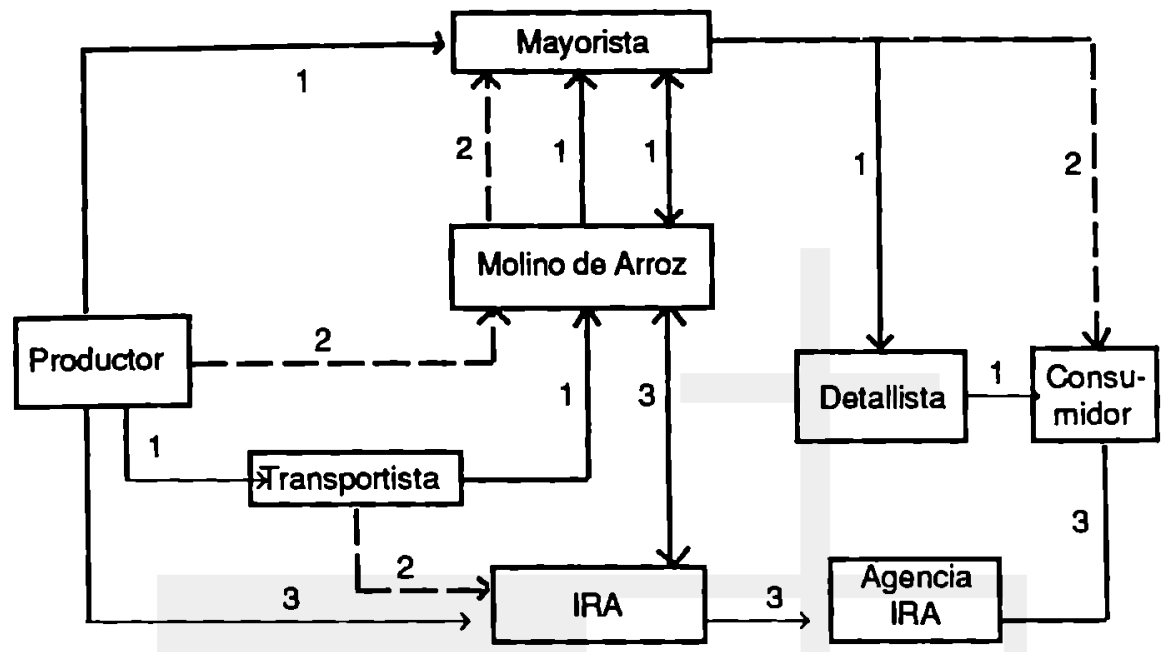

Fuente: Elaboración propia en base a investigación de campo.

Flujo 1: Forma predominante de abastecimiento del mercado

Flujo 2: Forma ocasional de abastecimiento del mercado.

Flujo 3: Forma de abastecimiento del mercado a través del IRA.

La medida en que este elemento se constituya en la variable determinante para las decisiones de siembra dependerá mucho del tipo de producto, tamaño de la explotación, condiciones económicas y, consecuentemente, de la racionalidad de los productores.

De esta manera, los pequeños productores de maiz y frijol señalan que más que los precios vigentes en el mercado, esperan que el invierno sea copioso y que comience en los meses esperados para iniciar la siembra. Es por esta razón y debido principalmente a la sequía recién pasada, que algunos agricultores no sembraron frijol durante el año agricola presente, lo cual demuestra claramente la influencia que poseen los factores climatológicos sobre las decisiones de siembra de los agricultores.

Por su parte, los pequeños productores de arroz -excepto los que disponen de un sistema de riego- sefalan también como un factor importante el clima, aunque la influencia de los precios de mercado ñ as despreciable para sus decisiones de siembra. Podria decirse que para ellos, tanto los precios como el clima influyen sobre sus decisiones de producción. 
CUADRO N 11

Productores de maiz y frljol: factores que Influyen sobre dec. de slembra (5)

\begin{tabular}{|l|c|}
\hline \multicolumn{1}{|c|}{ INFLUENCIAS } & $\begin{array}{c}\text { ASPECTOS TOMADOS } \\
\text { EN CUENTA } \\
\text { EN DECISIONES } \\
\text { DE PRODUCCION }\end{array}$ \\
\hline PRECIOS DE GARANTIA DEL IRA & 0.0 \\
\hline FACTOR CLIMATOLOGICO & 65.12 \\
\hline PRECIOS DEL MERCADO & 2.33 \\
\hline PRECIOS DEL INTERMEDIARIO & 4.65 \\
\hline COSTOS & 16.28 \\
\hline PRECIOS DEL IRA INTERMEDIARIOS Y COSTOS & 2.33 \\
\hline PRECIOS DEL IRA E INTERMEDIARIOS & 4.65 \\
\hline PRECIOS DEL INTERMEDIARIOY COSTOS & 2.33 \\
\hline PRECIOS DEL INTERMEDIARIO Y DEL MERCADO & 2.33 \\
\hline TOTAL $\%$ (N) & 100 \\
\end{tabular}

Fuente: IBID.

\section{CUADRO № 12}

Pequeños productores de arroz: factores que influyen sobre decislones de slembra (\%)

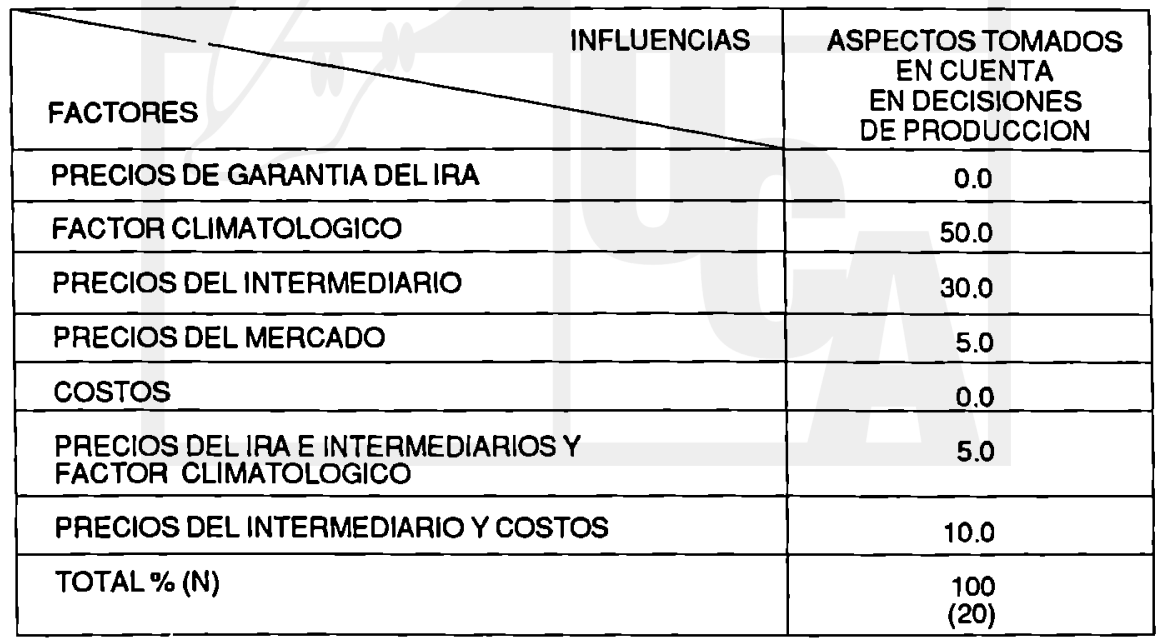

Fuente: IBID. 
Si se examina cuál es el elemento decisivo para los medianos y grande sproductores de arroz encuestados, es de notar cómo, entre una diversidad de factores, el criterio de rentabilidad desplaza al clima en importancia, aunque, como se dijo antes, el segundo influye en alguna medida.

\section{CUADRO № 13}

Grandes productores de arroz:

factores que Influyen sobre dec. de slembra

\begin{tabular}{|l|c|}
\hline INFLUENCIA & $\begin{array}{c}\text { ASPECTOS } \\
\text { TOMADOS EN } \\
\text { CUENTA EN } \\
\text { DECISIONES } \\
\text { DE PRODUCCION }\end{array}$ \\
\hline FACTOR CLIMATOLOGICO & 2 \\
\hline RENTABILIDAD DEL CULTIVO & 6 \\
\hline TOTAL & 8 \\
\hline
\end{tabular}

Fuente: IBID

Cabe aclarar que las condiciones climatológicas influyen en la medida que rezagan el periodo de siembra y no en el sentido de que los productores decidan sembrar o no exclusivamente en base a este aspecto. De alli que independientemente del tamaño de la explotación, es induscutible que este factor juega un papel decisivo en el proceso de producción de los granos básicos.

Otro aspecto importante a considerar de las condiciones climáticas es que, además de influir sobre las decisiones de producción, afectan los costos totales de los agricultores. A pesar de esto, en la mayoría de casos esto no se refleja en el precio, dado que en este tipo de productos, los costos no son los únicos determinantes del precio de venta.

II. Implicaciones de la formación de preclos de los productos agricolas de alimentación

\subsection{Precios de mercado al productor}

Genéricamente, el productor se relaciona con el capital comercial, con los comerciantes y con el Estado.

Para efectos del presente estudio, interesan particularmente las relaciones del productor con los comerciantes y el IRA; por lo que no se 


\section{CUADRO № 14}

Pequefios productores: Influencia de sequia sobre los costos (\%)

\begin{tabular}{|l|c|c|}
\hline \multicolumn{1}{|c|}{$\begin{array}{c}\text { INFLUENCIA } \\
\text { DE }\end{array}$} & $\begin{array}{c}\text { AFECTA } \\
\text { SUS } \\
\text { COSTOS }\end{array}$ & $\begin{array}{c}\text { TOTAL \% } \\
\text { (n) }\end{array}$ \\
\hline $\begin{array}{l}\text { SI LOSTERNATIVA } \\
\text { AFECTAN }\end{array}$ & 92.98 & $\begin{array}{c}100.0 \\
(57)\end{array}$ \\
\hline NO LOS & 7.02 & \\
\hline AFECTAN & & \\
\hline
\end{tabular}

Fuente: IBID

Excluye a los productores de arroz que tienen sistema de riego

\section{CUADRO N²15}

Pequeños productores: Influencla de sequia sobre el precio de venta (\%)

\begin{tabular}{|l|c|c|}
\hline \multicolumn{1}{|c|}{$\begin{array}{c}\text { INFLUENCIA } \\
\text { DE }\end{array}$} & $\begin{array}{c}\text { LAFECTAN } \\
\text { ELPRECIO } \\
\text { DE VENTA? }\end{array}$ & $\begin{array}{c}\text { TOTAL \% } \\
\text { (n) }\end{array}$ \\
\cline { 1 - 2 } SI LO & 40.0 & \\
AFECTA & 60.0 & 100.0 \\
NO LO & $(50)^{*}$ \\
AFECTA & & \\
\hline
\end{tabular}

Fuente: IBID

- Excluye a 7 productores de malz y frijol

ahondará en los vinculos con el capital comercial.

La relación entre el productor y el comerciante constituye el primer eslabón de la cadena de comercialización; es a la vez la más frecuente a este nivel, puesto que la vinculación con el IRA es limitada. 
Generalmente, las decisiones sobre el precio de venta en la relación productor-comerciante favorecen al segundo, dado el limitado poder de negociación del pequeño productor y la relativa y temporal sobre-oferta en la época en que es realizada la transacción; ocasionada por la necesidad de él mismo de vender inmediatamente su cosecha. Todas estas condicionantes obligan al pequeho agricultor a aceptar el precio propuesto por el negociante; lo que deriva en el hecho de que muchas veces ese precio no cubre los costos (especialmente en los casos del maíz y del frijol), precisamente porque aquél no es decidido directamente en base a éstos, sino que es determinado por la situación del mercado.

Es en ese sentido que los pequenos productores podrían considerarse como tomadores de precios. Téricamente, entonces, el mercado de granos por el lado de los productores se asemeja al de competencia perfecta, pues "cada uno de los agentes económicos es tan pequeño, en relación con el mercado total, que no puede ejercer influencia perceptible sobre el precio"1. Ahora bien, por el lado de los compradores, este supuesto básico de la competencia perfecta no se cumple; de alli que no se trate de "un mercado en el que hay una completa ausencia de competencia directa entre los agentes económicos"2. Pragmáticamente, pues, la estructura de mercado de granos básicos, por el lado de los demandantes, se caracteriza por el dominio de los mayoristas, quienes precisamente, en relación con el mercado, son relativamente grandes, por lo que sí pueden ejercer una influencia perceptible sobre el precio.

Respecto a la condición de libre movilidad de los recursos que supone este tipo de mercado, tenemos, en primer lugar que, evidentemente la configuración de la estructura agraria imposibilita su cumplimiento; esencialmente en lo referente a la propiedad de la tierra. En segundo lugar, la distribución de los insumos agrícolas es realizada bajo una forma que podría catalogarse como oligopólica.

Finalmente, la condición sine qua non de la competencia perfecta, consistente en el conocimiento perfecto del mercado por parte de los agentes económicos, dista mucho de poseer validez; no sólo porque los productores directos no estén informados acerca de los precios vigentes en el mercado, sino esencialmente porque la racionalidad de subsistencia que caracteriza a este tipo de agricultores les condiciona a que el precio no sea el criterio que guie sus decisiones de producción.

Bajo esta óptica, entonces, se estaría frente a un productor "irracional"; ya que no actúa de acuerdo a "sefiales pecuniarias", lo que contradeciría, desde todo punto de vista, cualquier intento de analogia del mercado de granos del país con una situación de competencia perfecta. 
Tomando como referencia las estructuras de costos oficiales para los granos básicos (elaboradas no sólo para pequefios productores, sino para la producción de granos independientemente de los tamafios de las explotaciones) $y$, pese a lo que los promedios implican, pueden detectarse algunas tendencias.

Para empezar, las variaciones de los costos totales observan una marcada correspondencia con las variaciones de los insumos (ver gráficos 1,2 y 3) para los tres granos estudiados, lo que permite evidenciar, en términos más generales, el mayor peso relativo de los insumos en las estructuras de costos del maiz, del frijol y del arroz.

Con el objeto de establecer una relación comparativa precios-costos y tomando como punto de partida los datos sobre los costos totales y rendimientos de los granos básicos, es posible calcular los costos unitarios (Cfr. cuadro 16). Se está consciente de las limitaciones de este procedimiento, pero es la manera más sencilla de visualizar el problema. Comparando los precios promedio al roductor (Cfr. cuadro $\mathrm{N}^{2} 17$ ) con los costos unitarios promedio se obtiene la relación contenida el cuadro $N^{2}$ 18.

El incremento en los costos totales de producción para el ano agricola 1986/87, respecto al 85/86 está intimamente relacionado con el aumento del costo de los insumos importados a causa de la devaluación oficial de Enero de 1986. Además del incremento del costo de los insumos, los costos unitarios del maiz y del arroz se vieron afectados por la baja en los rendimientos. Para el frijol, pese al incremento en los costos totales, el costo unitario se mantuvo gracias a los mejores rendimientos obtenidos en ese ano agricola.

Los precios promedio pagados al productor en el 86 , al igual que los costos, sufrieron un aumento significativo respecto al año anterior.

El comportamiento de los costos y los precios parece sugerir una relación directa entre ambos. Sin embargo, en la formación de precios de los granos básicos debe tomarse en cuenta la participación de otros elementos, no menos determinantes, que hacen que los incrementos en los costos no se traduzcan íntegramente al precio $y$, por tanto, que relativizan esa relación.

Si bien el precio no es una decisión tomada por el productor directo, tampoco es una decisión arbitraria por parte del comerciante. Los costos de producción, aunque no es medida contablemente estricta, son tomados en cuenta por el productor, si no para fijar el precio, al menos para aceptarlo. En esta medida, los costos imponen un límite al poder de negociación del comerciante. 


\section{GRAFICO Ne 1}

\section{COSTOS DE PRODUCCION DEL MAZ \\ PERIODO $1977 / 78$ - 1987/88 (COLONES POR MANZANA)}

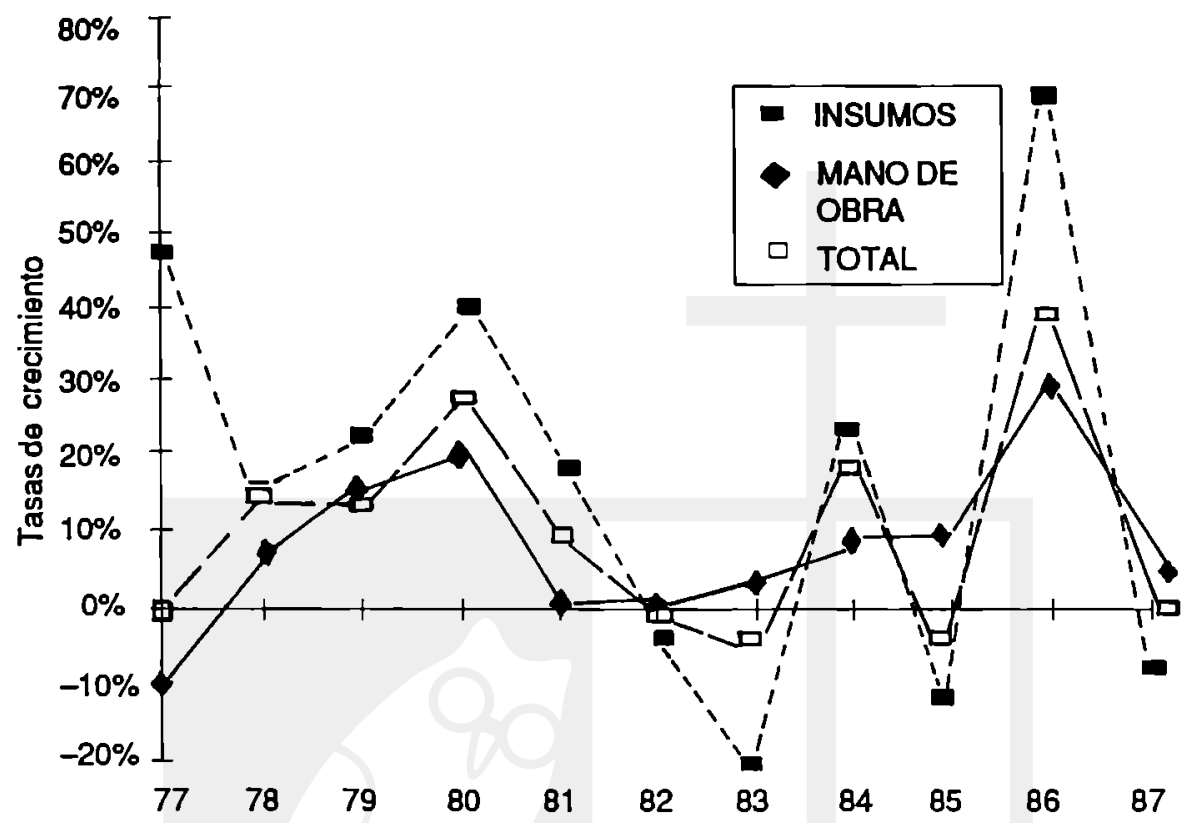

Fuente: Elaboración propia en base a datos proporcionados Por D.G.E.A.

Digitalizado por Biblioteca "P. Florentino Idoate, S.J." 


\section{COSTOS DE PRODUCCION DEL FFIJOL \\ PERIODO 1977/78 - 1987/88 (COLONES POR MANZANA)}

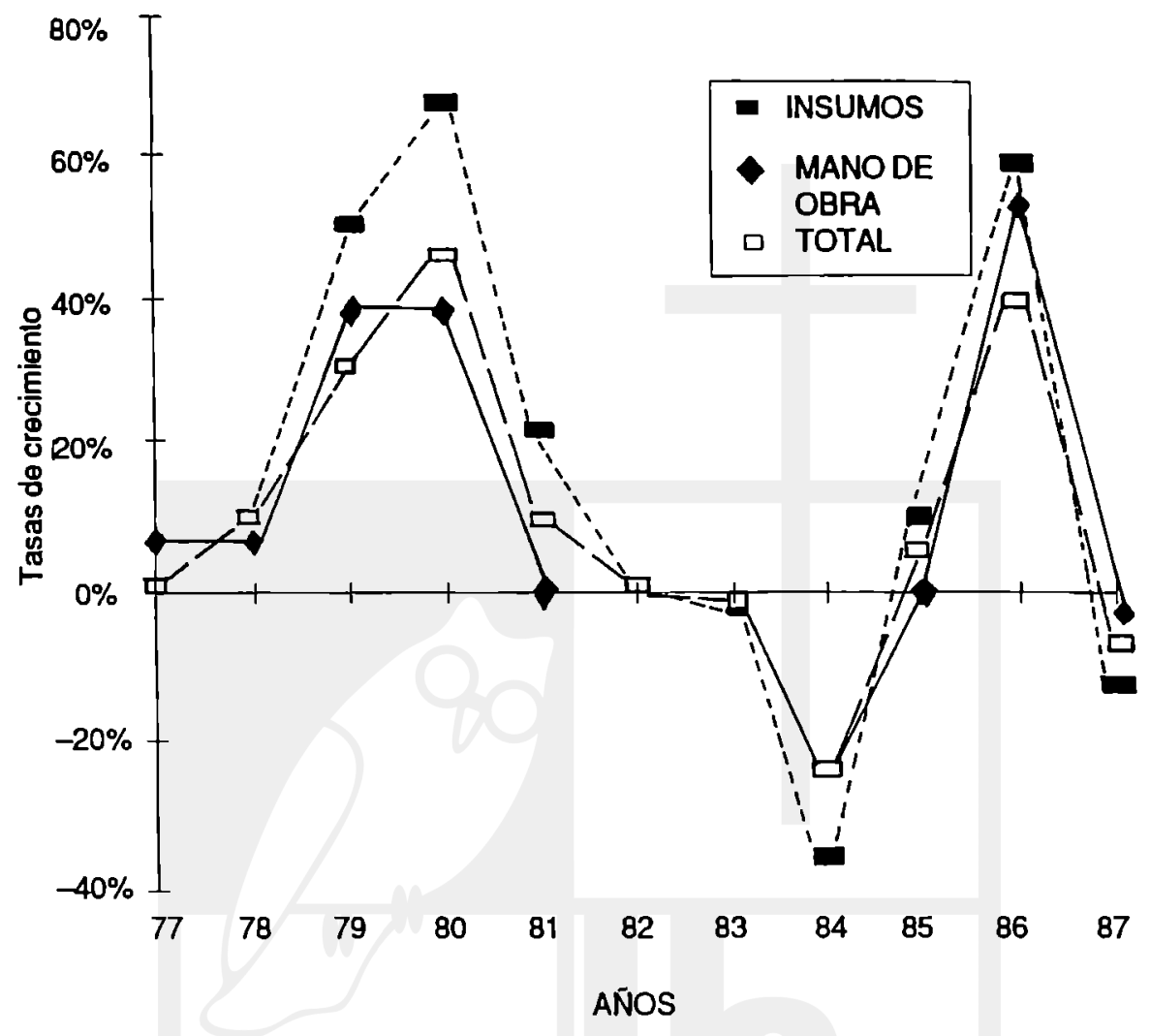

Fuente: IBID. 


\section{COSTOS DE PRODUCCION DEL ARROZ PERIODO 1977/78 - 1987/88 (COLONES POR MANZANA)}

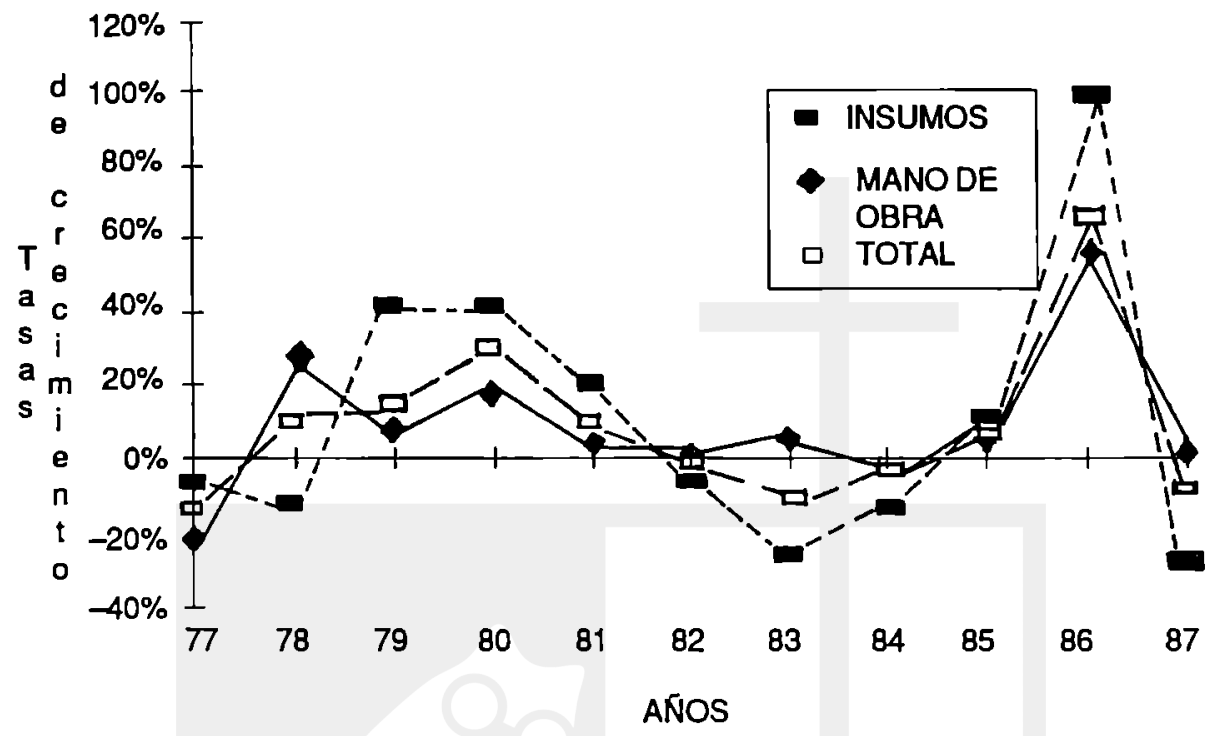

Fuente: IBID.

Digitalizado por Biblioteca "P. Florentino Idoate, S.J." Universidad Centroamericana José Simeón Cañas 


\section{CUADRO N2 16}

Costos totales, rendimlentos y costos unitarlos de los granos

\begin{tabular}{|c|c|c|c|c|c|c|c|c|c|}
\hline \multirow[b]{2}{*}{ ANO } & \multicolumn{3}{|c|}{ Malz Consumo a) } & \multicolumn{2}{|l|}{ Frl]ol(b) } & \multicolumn{4}{|c|}{ Arroz Granzac) } \\
\hline & C.T. & REND. & C. U. & C.T.. & REND. & c. U. & C.T.. & REND. & c. U. \\
\hline 87 & 1175.88 & 27.5 & 42.76 & 1233.50 & 11.6 & 106.34 & 1665.46 & 55.0 & 30.28 \\
\hline 81 & 1257.20 & 27.5 & 45.72 & 1330.35 & 11.7 & 113.71 & 1793.15 & 55.0 & 32.6 \\
\hline 82 & 1243.50 & 26.4 & 47.10 & 1330.35 & 10.5 & 126.70 & 1756.48 & 48.1 & 36.52 \\
\hline 89 & 1182.47 & 27.4 & 43.16 & 1317.76 & 11.4 & 115.59 & 1639.73 & 52.2 & 31.41 \\
\hline 84 & 1432.21 & 33.0 & 43.40 & 1002.62 & 12.8 & 78.33 & 1587.53 & 62.9 & 25.24 \\
\hline 85 & 1349.52 & 29.7 & 45.44 & 1031.61 & 9.0 & 114.62 & 1684.03 & 60.6 & 27.79 \\
\hline 86 & 1898.47 & 25.8 & 73.58 & 1445.46 & 12.6 & 114.72 & 2844.31 & N.D. & - \\
\hline 87 & 1900.32 & N.D. & - & 1335.82 & N.D. & 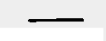 & 2632.43 & N.D. & - \\
\hline
\end{tabular}

Fuente: Elaborado con datos proporcionados por D.G.E.A.

C.T. Costos totales por manzana

REND: Rendimiento en quintales

C.U.: Costo Unitario en colones por quintal

a) : Con rendimientos totales de malz y costos de malz-consumo

b) : Con rendimientos totales de frijol

c) : Con rendimientos totales de arroz granza.

\section{CUADRO N 17}

Preclos promedio anuales al productor

$(6 \times q q)$

\begin{tabular}{crrrrrr}
\hline & \multicolumn{2}{c}{ MAIZ } & \multicolumn{2}{c}{ FRIJOL } & \multicolumn{2}{c}{ ARROZ } \\
\cline { 2 - 7 } AÑO & PRECIO & \% ANUAL & PRECIO & $\%$ & PRECIO & \multicolumn{1}{c}{$\%$} \\
\hline 83 & 21.07 & - & 53.73 & - & 31.75 & - \\
84 & 21.88 & 3.83 & 49.85 & -8.92 & 20.89 & -34.21 \\
85 & 20.79 & -4.98 & 62.43 & 25.23 & 21.52 & 3.02 \\
86 & 30.46 & 46.51 & 94.08 & 50.70 & 29.06 & 38.75 \\
$87^{*}$ & 36.41 & 19.53 & 94.27 & 0.20 & 40.95 & 37.14 \\
\hline
\end{tabular}

- Hasta Junio/87

Fuente: D.G.E.A.

Dentro de este marco, el incremento en el costo de los insumos explica, en cierta forma, la elevación el precio promedio al productor para 1986.

Esta razón no es suficiente, por lo que deben ser tomados en cuenta otros factores que contribuyeron al fenómeno. 
Relación preclo promedlo/costo unitario

\begin{tabular}{cccc}
\hline ANO & MAIZ & FRIJOL & ARROZ \\
\hline 1983 & 0.49 & 0.47 & 1.01 \\
1984 & 0.50 & 0.64 & 0.83 \\
1985 & 0.46 & 0.54 & 0.77 \\
1986 & 0.63 & 0.82 & - \\
\hline
\end{tabular}

Fuente: Elaboración con datos proporcionados por DGEA

Uno de ellos fue la reducción de la producción en los casos específicos del maíz y del arroz. La producción de frijol, al contrario, aumentó en el periodo referido gracias a los mejores rendimientos; esto a su vez permitió que el costo unitario del frijol se mantuviera. Pese a esto, su precio promedio fue el que experimentó la mayor alza del 85/86 al 86/87.

El planteamiento de posibles escenarios tal vez ayude a la explicación de tal contingencia.

Por una parte, sumado al efecto de la reducción de la producción (maiz y arroz), probablemente otro elemento que acentuó la elevación del precio al productor (maíz, arroz y especificamente, frijol), fue la mayor demanda por parte de los intermediarios ante las expectativas de mayores incrementos en los costos, no sólo para los productores, sino también para ellos mismos, a causa de la devaluación. Esto les permitiría, además, justificar mayores precios de venta.

Por otro lado, existe la posibilidad de que al concluir el año agrícola iniciado en mayo de 1986 (en mayo de 1987) la sequía fuese ya un fenómeno perceptible; empujando a los intermediarios a demandar más grano para aprovechar una probable futura escasez.

Ambas posibilidades se reducen al incremento de la demanda especulativa por parte de los intermediarios, ante las expectativas de la situación posterior del mercado.

En un contexto de formación de precios donde la oferta y la demanda tienen una participación determinante, esos elementos deben considerarse en el análisis de las variaciones del precio al productor.

Conjugando la acción de los agentes y variables del mercado, puede sostenerse la idea de que éste es el que determina, en última instancia, la proporción en que el precio al productor cubra sus costos.

En el ejemplo observado, la situación del mercado pudo contribuir a 
que el precio cubriera en mayor cuantia el costo unitario para el periodo 1986/87 (Cfr. cuadro Ne 18).

Tendencialmente, el precio promedio pagado al productor no cubre los costos unitarios promedio; aunque, los precios del arroz cubren en mayor proporción sus costos.

La relativa rentabilidad de este producto puede ser atribuida, por una parte, al hecho de que los intermediarios privados participan menos en su comercialización que en la del maiz y el frijol.

Según datos oficiales, del total del volumen comercializable de maiz, frijol y arroz, el mercado controla aproximadamente el $80 \%, 70 \%$ y $50 \%$ respectivamente; el resto es comercializado a trvés del IRA. ${ }^{3}$

Por otra parte, la más alta rentabilidad puede explicarse porque el arroz es un producto cultivado en una proporción considerable por productores medianos y grandes.

De acuerdo al Tercer Censo Nacional Agropecuario, el $51 \%$ de la producción de arroz es asegurado por explotaciones medianas y grandes. Los productores mencionados gozan de mayor poder de negociación; lo que les permite influir más en el precio al que venderán al intermediario. Además, muchas veces son los mismos grandes productores los que comercializan el grano, estableciendo precios que si garantizan una ganancia.

En consecuencia, el área de fijación del precio por parte de los intermediarios es menor en este producto, lo que contribuye a su mayor estabilidad.

Esta composición de la comercialización favorece al pequeho productor.

En general, dada la estructura de mercado de granos, el precio de compra al productor constituye una vía de redistribución en contra de éste y a favor del intermediario.

Si se hace referencia a los intermediarios como totalidad, es válido sostener que son ellos los que se apropian del diferencial de precios, que es a favor de ellos que opera la redistribución vía precios al productor

En un nivel más específico y conociendo la estructura de distribución, realmente el precio favorece al mayorista (especulador o acopiador); puesto que para éste, el margen de comercialización no constituye una especie de salario, sino una ganancia comercial; dadas sus respectivas y distintas condiciones económicas. Es decir, "...Aunque ciertamente al comerciante compra para vender más caro, el dilerencial que obtiene, más que constituir un beneficio, es un ingreso que bien equivale a lo que obtendria de vender su fuerza de trabajo"4 


\subsection{Preclos de garantia al productor}

Según entrevista a funcionarios del IRA, ante la pregunta de cuál es el criterio para la fijación del precio de garantía, respondieron que "el IRA fija los precios según como estén en el mercado; calcula costos promedios por manzana para conocer el precio de costo; pero no se ponen en práctica para la fijación del precio de garantia. Sabemos que este método es el ideal, pero no lo practicamos y nos guiamos por el mercado"5

El criterio es el mercado, aunque un criterio condicionado. Por una parte, la capacidad total de almacenamiento del IRA (calculada en 2, 375695 qq para 1966)6, sólo representa porcentajes reducidos de la producción comercializable de granos (como se citaron más arriba). Por otra parte, el IRA "...cuenta con el apoyo financiero que le brinda el BCR a través de una linea de crédito por 150 millones de colones, sin embargo, tales fondos no son suficientes... En parte la insuficiencia de fondos es debido a que el IRA en las operaciones de compra-venta, incurre en pérdidas que alcanzan la cifra de aproximadamente 50 millones de colones y los cuales tienen que ser reembolsados por el Gobierno para que pueda continuar con sus actividades reguladoras... Pero la suma todavia no ha sido reembolsada. Esto a su vez repercute en una reducción de fondos disponibles para la línea de crédito rotativo." ${ }^{7}$ A esto habria que sumar los problemas de carácter administrativo.

Individualmente, el IRA podría ser considerado como un "comprador líder", como el mayor intermediario individual en el mercado; sin embargo, los privados como un todo controlan la mayor parte de la producción comercializable. Desde este punto de vista, no es atinado suponer que "...podría eliminar a todos sus rivales mediante una guerra de precios"8. De tal forma que agrupando los agentes en sector privado y sector estatal, el radio de acción de los precios de garantia es restringido, limitado por la capacidad de compra y de almacenamiento del IRA.

Se pone en tela de juicio la función reguladora de los precios de garantia; más parece ser que el mercado regula al IRA y no lo contrario; es decir, parece existir un efecto arrastre de los precios del mercado sobre los precios de, garantia. Los precios de garantía pueden apreciarse en el cuadro $\mathrm{N}^{2} 19$ y en el $\mathrm{N}^{2} 20$, su relación con los costos unitarios.

Evidentemente, los precios del IRA son mayores que los precios promedio, pero al no basarse en el criterio de costos, no garantizan cubrirlos en su totalidad, excepto en el caso del arroz, producto en cuya comercialización logra mayor participación.

El precio de garantía juega un papel redistributivo en sentido contrario al precio del intermediario privado. La diferencia radica en que la racio- 
nalidad del IRA es la de "comprar caro para vender barato". Este subsidio parcial es efectivo siempre y cuando el precio de mercado sea menor que el de garantla; de lo contrario, el productor que vende al IRA obtendrá, además de la pérdida absoluta, una pérdida relativa respecto a los productores que venden a los comerciantes.

El criterio "ideal" de costos depende, para su puesta en práctica, también de la participación cuantitativa del IRA en la comercialización.

El problema del precio al productor no es aislado, puesto que éste, además de oferente es demandante, no sólo de medios de producción, sino también de medios de vida. La comercialización de sus productos asegura buena parte de sus ingresos. Precisamente el precio es la base de este tipo de ingresos. Al sufrir un deterioro el precio, también su capacidad adquisitiva se ve desmejorada.

\section{CUADRO N²19}

Preclos de garantla IRA en $x$ qq

\begin{tabular}{rr|r|r}
\hline COSECHA & MAIZ & FRIJOL & ARROZ GRANZA \\
\hline $1980-81$ & 24.00 & 100.00 & 33.00 \\
$1981-82$ & 24.00 & 100.00 & 33.00 \\
$1982-83$ & 23.25 & $65.00-75.00$ & 33.00 \\
$1983-84$ & 30.00 & 80.00 & 37.00 \\
$1984-85$ & 30.00 & 80.00 & 37.00 \\
$1985-86$ & 31.00 & $80-100.00$ & 38.00 \\
$1986-87$ & 45.00 & 120.00 & 46.00 \\
\hline
\end{tabular}

Fuenle: IRA-Unidad de Planificación

\section{CUADRO № 20}

Relación Pr garantla/costo unltarlo promedlo

\begin{tabular}{cccc}
\hline COSECHA & MAIZ & FRIJOL & ARROZ \\
\hline 1980 & 0.56 & 0.94 & 1.09 \\
1981 & 0.52 & 0.88 & 1.01 \\
1982 & 0.49 & 0.59 & 0.90 \\
1983 & 0.70 & 0.69 & 1.18 \\
1984 & 0.69 & 1.02 & 1.47 \\
1985 & 0.68 & 0.87 & 1.37 \\
1986 & 0.61 & 1.05 & - \\
1987 & - & - & - \\
\hline
\end{tabular}

Fuente: IDGEA

IRA 
En términos generales, existe la tendencia al deterioro de los términos de intercambio entre el productor de granos y el resto de la economia (Cir. cuadro Ne 21); fenómeno que puede ser atribuido a diversas causas.

En primer lugar, aunque la inflación y la progresiva devaluación del colón afectan, tanto los costos de los productos agrícolas como los de los no agrícolas, el factor determinante está en las distintas formas de fijar el precio para ambos tipos de bienes.

Si bien el aumento del precio de los insumos importados infla los costos de los productos en cuya elaboración intervienen; en el caso de los productos manufacturados son trasladados fácilmente al precio (reforzado este hecho por la tendencia de los empresarios a ampliar su capacidad ociosa bajo el actual contexto); lo que no sucede en el caso de los granos.

Lo anterior se manifiesta en que, en los últimos anos, el índice de precios del resto de la economía respecto al índice de precios de los granos básicos se ha incrementado.

La formación de precios de la economia salvadoreha opera en contra del pequeño agricultor en su doble carácter (oferente y demandante).

\section{CUADRO N²1-A}

Preclos relatlvos agropecuarlos en base al deflactor Impliclto del PIB

\begin{tabular}{|c|c|c|c|c|c|c|c|c|}
\hline & \multicolumn{3}{|c|}{ DEFLACTORES IMPLICTTOS } & \multicolumn{3}{|c|}{ ESTRUCTURA POACENTUAL PIB } & \multicolumn{2}{|c|}{ PRECIO RELATIVO } \\
\hline & $\begin{array}{l}\text { Sector } \\
\text { Agrop. }\end{array}$ & $\begin{array}{l}\text { Indice } \\
\text { General }\end{array}$ & $\begin{array}{l}\text { Pealo } \\
\text { Econ. }\end{array}$ & $\begin{array}{l}\text { Sector } \\
\text { Agrop. }\end{array}$ & PIB & $\begin{array}{l}\text { Perto } \\
\text { Econ. }\end{array}$ & $\begin{array}{l}\text { Sector A } \\
\text { A. econ. }\end{array}$ & נo78-100 \\
\hline 1978 & 239.2 & 209.9 & 201.0 & 23.38 & 100.00 & 76.62 & 1.19 & 100.00 \\
\hline 1979 & 282.7 & 239.0 & 224.7 & 24.64 & 100.00 & 75.36 & 128 & 105.69 \\
\hline 1980 & 294.9 & 271.1 & 262.9 & 25.57 & 100.00 & 74.43 & 1.12 & 94.23 \\
\hline 1981 & 267.4 & 286.6 & 293.4 & 26.10 & 100.00 & 73.90 & 0.91 & 76.57 \\
\hline 1982 & 276.5 & 314.9 & 328.6 & 26.36 & 100.00 & 73.64 & 0.84 & 70.68 \\
\hline 1983 & 297.3 & 353.7 & 372.8 & 25.32 & 100.00 & 74.68 & 0.80 & 68.90 \\
\hline 1984 & 308.9 & 397.1 & 427.4 & 25.58 & 100.00 & 74.42 & 0.72 & 60.72 \\
\hline 1985 & 350.7 & 478.7 & 520.9 & 24.81 & 100.00 & 75.19 & 0.87 & 56.26 \\
\hline
\end{tabular}

Fuente: Revistas Mensuales del BCR.

\subsection{Preclos de mercado al consumidor}

La escasez real posibilita la especulación con los granos alimenticios, dada su estructura de distribución. El resultado del acaparamiento es el alza de los precios en el mercado. 


\section{Preclos relatlvos de los granos básicos \\ en base al deflactor impliclto del PIB}

\begin{tabular}{|c|c|c|c|c|c|c|c|c|}
\hline & \multicolumn{3}{|c|}{ DEFLACTORES IMPLICITOS } & \multicolumn{3}{|c|}{ ESTRUCTUAA PORCENTUAL PIE } & \multicolumn{2}{|c|}{ PAECIO RELATIVO } \\
\hline & $\begin{array}{l}\text { Granos } \\
\text { Báslcos }\end{array}$ & $\begin{array}{l}\text { Indlce } \\
\text { General }\end{array}$ & $\begin{array}{l}\text { Reoto } \\
\text { Econ. }\end{array}$ & $\begin{array}{l}\text { Sector } \\
\text { Agrop. }\end{array}$ & PIB & $\begin{array}{l}\text { Resto } \\
\text { Econ. }\end{array}$ & $\begin{array}{l}\text { Granoe B } \\
\text { A. econ. }\end{array}$ & $1878=100$ \\
\hline 1978 & 291.8 & 209.9 & 207.0 & 3.46 & 100.00 & 86.54 & 1.41 & 100.00 \\
\hline 1979 & 242.5 & 239.0 & 238.9 & 3.66 & 100.00 & 96.34 & 1.02 & 72.02 \\
\hline 1980 & 282.1 & 271.1 & 270.7 & 3.91 & 100.00 & 96.09 & 1.04 & 73.92 \\
\hline 1981 & 309.6 & 286.6 & 285.6 & 4.02 & 100.00 & 05.98 & 1.08 & 76.80 \\
\hline 1982 & 331.7 & 314.9 & 314.3 & 3.57 & 100.00 & 96.43 & 1.06 & 74.86 \\
\hline 1983 & 372.7 & 353.7 & 352.9 & 3.82 & 100.00 & 96.18 & 1.08 & 74.91 \\
\hline 1984 & 349.9 & 397.1 & 399.3 & 4.52 & 100.00 & 95.48 & 0.88 & 62.15 \\
\hline 1985 & 347.3 & 478.7 & 484.3 & 4.09 & 100.00 & 95.91 & 0.72 & 50.86 \\
\hline
\end{tabular}

Fuente: Revistas Mensuales del BCR.

Tomados de: Lort M. y A. Trigueros. Ibid.

Como consecuencia de las pérdidas ocasionadas por la sequla en $1987 / 88$, el precio del frijol se elevó en forma desmedida, alcanzando hace algunos meses el precio de $5.50 \times$ Lb., pues este grano fue el más afectado por la falta de lluvias. (Ctr. cuadro $\mathrm{N}^{2} 22$ ).

En otras palabras, la tendencia alcista del precio se vio favorecida por el agravamiento de la escasez real y acentuada por la escasez resultante del acaparamiento. Basta comprarar los precios de 1987 con los del primer semestre de 1988 para darse cuenta de lo anterior. (Cfr. cuadro Ne 23).

Tomando como referencia el índice de precios al consumidor, puede deducirse el peso que el alza del precio de los granos tiene sobre la estructura de consumo. (Cfr. cuadro $\mathrm{N}^{2} 24$ ).

En un esquema simplificado de comercialización, donde la relación productor-consumidor fuese inmediata (sin intermediarios), el alza del precio via escasez favoreceria al productor; es decir, cabría sostener la posibilidad de un efecto redistributivo desde el consumidor hacia el productor. Dada la compleja red de distribución, ese efecto va desde el consumidor hacia el mayorista.

Además del incremento del precio atribuible propiamente a la presión de la demanda sobre la oferta, existe otro factor que también altera el precio: cada agente mediador agrega lo que considera su remuneración en función de su posición dentro de los canales de comercialización. De alli que los márgenes que van desde transporte hasta ganancia comercial forman parte del precio al consumidor, ampliándose en la medida que tales agentes incurren en mayores gastos y de acuerdo a la espe- 
culación que hagan según sus expectativas respecto a la situación del mercado.

\section{CUADRO N²22}

Superilele, producción y pérdldas por sequla 1987-88

Superficle (Mz)

Producclon (qq)

\begin{tabular}{lrrrrrrr}
\hline Rubro & Cultivada & Afecta. & $\%$ & Esperada & Real & Perdlda & $\%$ \\
\hline Malz & 398500 & 24600 & 6.2 & 13054000 & 12575900 & 478100 & 3.7 \\
Frijol & 89300 & 68900 & 77.2 & 1228300 & 531000 & 697300 & 56.8 \\
Arroz C & 14200 & 4500 & 32.0 & 932700 & 731550 & 201150 & 21.6 \\
\hline
\end{tabular}

Fuen1o: IRA

\section{CUADRO N2 23-A}

Preclos comunes mensuales de granos báslcos a nivel de consumldor plaza de San Salvador $1987 \div$ x lb.

\begin{tabular}{llll}
\hline Meses & Malz blanco & Arroz & Frljol \\
\hline Enero & 0.45 & 0.90 & 1.25 \\
Febrero & 0.45 & 1.00 & 1.25 \\
Marzo & 0.45 & 1.00 & 1.25 \\
Abril & 0.50 & 1.10 & 1.25 \\
Mayo & 0.50 & 1.10 & 1.25 \\
Junio & 0.55 & 1.40 & 1.25 \\
Julio & 0.55 & 1.40 & 1.25 \\
Agosto & 0.55 & 1.40 & 1.20 \\
Septiembre & 0.55 & 1.40 & 1.20 \\
Octubre & 0.50 & 1.30 & 1.20 \\
Noviembre & 0.50 & 1.30 & 1.60 \\
Diciembre & 0.50 & 1.40 & 1.65 \\
\hline
\end{tabular}

Fuento: DGEA 
CUADRO N²3-B

Evoluclón mensual durante 1988 de los preclos de los granos básico escogidos $\mathrm{x}$ Lb.

\begin{tabular}{lcccccc}
\hline & Enero & Febrero & Marzo & Abrll & Mayo & Junlo \\
\hline Maiz & 0.50 & 0.50 & 0.50 & 0.50 & 0.60 & 0.60 \\
Frijol rojo & 1.90 & 2.10 & 2.75 & 3.60 & 3.60 & 4.25 \\
ArToz & 1.40 & 1.40 & 1.50 & 1.60 & 1.60 & 1.60 \\
\hline
\end{tabular}

Fuente: DGEA. Tomado de Rivera C. "Producción de Alimentos y Desbalances Macroeconómicos" pp. 21.

\section{CUADRO N 24}

Variación mensual del Indlce de preclo al consumidor en 1988 (base $1978=100$ )

\begin{tabular}{lccccccc}
\hline & Enero & Febrero & Marzo & Abril & Mayo & Junio & Ene-Jun. \\
\hline Alimento & 1.7 & 2.0 & 5.0 & 5.3 & 2.8 & 3.4 & 3.4 \\
Vestuario & 0.4 & 0.1 & 0.2 & 0.6 & 1.0 & 0.6 & 0.5 \\
Vivienda & 0.2 & 0.1 & 0.1 & 0.1 & 0.9 & 0.3 & 0.3 \\
Misceláneos & 4.4 & 1.8 & 0.1 & 1.2 & 1.3 & 1.2 & 1.1 \\
General & 1.7 & 1.4 & 2.7 & 2.8 & 2.0 & 2.2 & 2.1 \\
\hline
\end{tabular}

Fuente: MIPLAN. Tomado de Rivera C. op. cit. pp. 22.

En un contexto de inflación, si bien el productor no tiene la capacidad de trasladar integramente el incremento del costo de los insumos al precio, los intermediarios (especialmente mayoristas) si pueden trasladar al precio final el aumento en sus gastos de comercialización y hasta exigir un margen adicional.

Por tanto, el hecho de que los costos del productor no se reflejan totalmente en el precio pagado a éste, no significa una ventaja para el consumidor, ya que los representantes de los canales de comercialización se encargan de agregar al precio los márgenes respectivos.

\subsection{Regulación de preclos al consumidor}

En b que se refiere a las regulaciones directas, el IRA establece precios de venta al consumidor con el objetivo formal de "evitar que éstos paguen niveles exagerados de precios"9. 
A ser establecidos los mismos de acuerdo al mercado10, lo úinico que garantizan es que sean menores, aunque la relación precio de mercado/precio IRA indica que la diferencia entre ambos no es muy amplia. (CIr. cuadro $\left.N^{0} 26\right)$.

Los problemas propios de la institución y el reducido volumen de producto que comercializa hacen que la regulación directa del precio al consumidor no sea realmente efectiva.

La mencionada inefectividad está referida al grado en que los objetivos formales de la institución no son alcanzados: la regulación de precios al consumidor es inefectiva en la medida que éstos no son ca-

CUADRO NR 25

Indices simples (base 1978) de preclos en plaza al consumidor

\begin{tabular}{rrrr}
\hline ANO & MAIZ & FRIJOL & \multicolumn{1}{c}{ ARROZ } \\
\hline 1980 & 89.66 & 141.03 & 95.24 \\
1981 & 96.55 & 146.15 & 101.59 \\
1982 & 100.00 & 126.92 & 112.70 \\
1983 & 117.24 & 108.97 & 126.98 \\
1984 & 120.69 & 102.56 & 126.98 \\
1985 & 106.90 & 120.51 & 117.46 \\
\hline
\end{tabular}

Fuenle: Elaborado con datos de la DGEA

paces de influir significativamente en el mercado. En esta línea están ubicadas algunas investigaciones acerca del papel del IRA, las cuales afirman que "la acción reguladora y abastecedora del Estado no ha logrado tener influencia en los precios al consumidor, debido a la poca capacidad financiera para adquirir los productos, a la falta de almacenamiento..."11, aunque actualmente queda desvirtuada la posibilidad de que "para lograr una influencia en la comercialización el IRA debería adquirir el equivalente a un $20 \%$ de la producción nacional como minimo"12; ya que ese porcentaje ha llegado a alcanzarse, sin mayores implicaciones en la estructura de comercialización.

Otro estudio menciona que "el IRA no ha sido ni es capaz de manipular el mercado nacional de granos básicos, puesto que su carácter de mediatizador entre productor-consumidor, obliga a que su función "reguladora" y "abastecedora" no logre consolidarse"13.

Los precios de garantía al consumidor también se ven afectados por 
Relación preclo de venta IRA y preclo del mercado

\begin{tabular}{|c|c|c|c|c|c|c|c|c|c|}
\hline \multirow[b]{2}{*}{ Años } & \multicolumn{3}{|c|}{ MAIZ } & \multicolumn{3}{|c|}{ FAWOL } & \multicolumn{3}{|c|}{ ARAOZ } \\
\hline & Mercado & IAA & Relac. & Mercado & IRA & Relec. & Mereado & IRA & Pelec. \\
\hline $\begin{array}{l}1980 \\
1981\end{array}$ & $\begin{array}{l}0.25 \\
0.28\end{array}$ & $\begin{array}{l}0.217 \\
0.235\end{array}$ & $\begin{array}{l}87 \\
84\end{array}$ & $\begin{array}{l}1.09 \\
1.15\end{array}$ & $\begin{array}{l}0.70 \\
1.00\end{array}$ & $\begin{array}{l}64 \\
87\end{array}$ & $\begin{array}{l}0.59 \\
0.64\end{array}$ & $\begin{array}{l}0.53 \\
0.55\end{array}$ & 80 \\
\hline 1982 & 0.29 & 0.235 & 81 & 0.99 & 1.00 & 101 & 0.65 & 0.55 & $\begin{array}{l}86 \\
85\end{array}$ \\
\hline 1983 & 0.35 & 0.235 & 67 & 0.34 & 0.60 & 71 & 0.81 & 0.55 & 68 \\
\hline 1984 & 0.36 & 0.235 & 65 & 0.79 & 0.60 & 76 & 0.82 & 0.55 & 67 \\
\hline 1985 & 0.315 & 0.315 & 100 & 0.99 & 0.60 & 61 & 0.745 & 0.55 & 74 \\
\hline 1986 & 0.41 & 0.315 & 76 & 1.25 & 0.60 & 48 & 0.77 & 0.55 & 71 \\
\hline $1987^{\circ}$ & 0.51 & 0.45 & 80 & 1.25 & 1.00 & 80 & 1.20 & 0.80 & 66 \\
\hline
\end{tabular}

Fuenle: IRA

- Precios provisionales del mercado.

los precios de mercado, aunque se mantengan en un nivel inferior; los precios del IRA parecen seguir la trayectoria de los del mercado. Esta situación se expresa en los gráficos $N^{2} 4, N^{2} 5$ y $N^{2} 6$.

Visto el papel de las regulaciones estatales dentro del marco global de las políticas económicas y sus objetivos, la inefectividad en la regulación directa de los precios de los granos básicos se vuelve contraproducente a la política de regulación directa de los salarios. Puede decirse, en este sentido, que existe cierta incompatibilidad entre ambas medidas, si el objetivo al que tienden es la reducción del costo salarial.

Dentro de ese marco, el Estado también juega el papel de regulador indirecto de los precios a través de la politica de importaciones, con la cual se pretende lograr un abastecimiento adecuado del mercado. De esta manera, las importaciones son un complemento de las regulaciones directas de los precios. El IRA es el organismo estatal autorizado para la comercialización extema de granos básicos; por lo mismo, desde una visión macroeconómica, el criterio de efectividad reguladora del IRA debe incluir la efectividad de la politica de importaciones en cuanto a su adecuación, ya sea cuantitativa o temporalmente $y$, por consiguiente, en cuanto a su influencia sobre los precios.

Estáticamente, la inefectividad de tal politica puede observarse en el hecho de que las importaciones de frijol, v.gr., realizadas al principio de 1988 no fueron suficientes para detener el alza que experimentó el precio de este grano como consecuencia de la sequia; por el contrario, se procedió a importar luego que apareció el problema.

En otros términos, el papel de equilibradora ex-post que adquiere la política de importaciones impide su efectividad. 


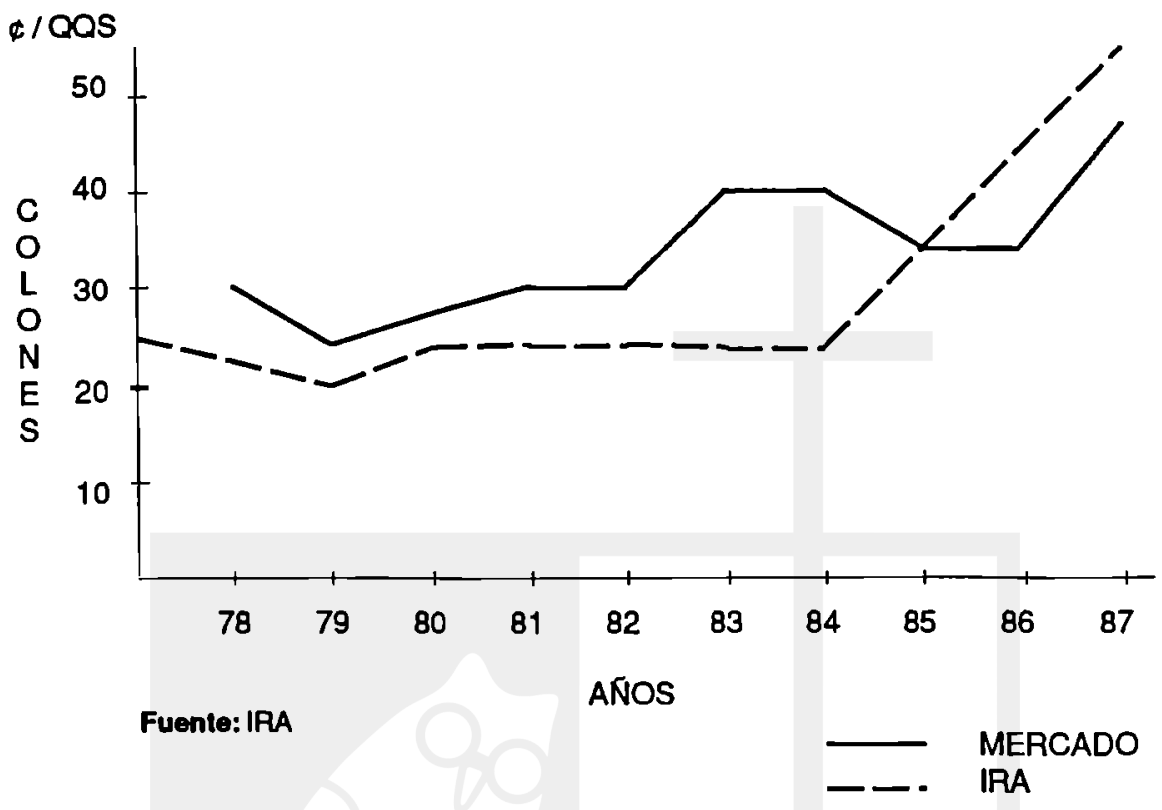

Dinámicamente, el papel de las importaciones será tratado en el apartado siguiente. Cabe adelantar que, en el largo plazo, la política de importaciones da cuenta de su falla de adecuación.

La restringida función del Estado como regulador no significa, de ninguna manera, que el desaparecimiento del IRA no acarreraria marcadas consecuencias. Tal situación equivaldria a la total eliminación de los subsidios estatales a los granos y la consecuente elevación de los precios al ser dominado todo el mercado por los privados.

\subsection{Dinámica de los precios de los productos agrícolas de alimen- taclón}

En el caso de El Salvador, un estudio acerca de la elasticidad-ingreso de la producción agrícola en dos períodos (1959/1971 y 1971/1979) demostró que la producción fue menos elástica en el segundo que en el primero. En efecto, se calculó que para el maiz, la elasticidad ingreso pasó de 1.5 a 1.14; para el frijol, de 2.08 a 0.91 y para el arroz, de 2.54 para el primer periodo (no pudo calcularse la del segundo), pero la producción creció a una tasa menor que en el lapso 1959/1971 ${ }^{14 .}$ 
$\$$ /OQS

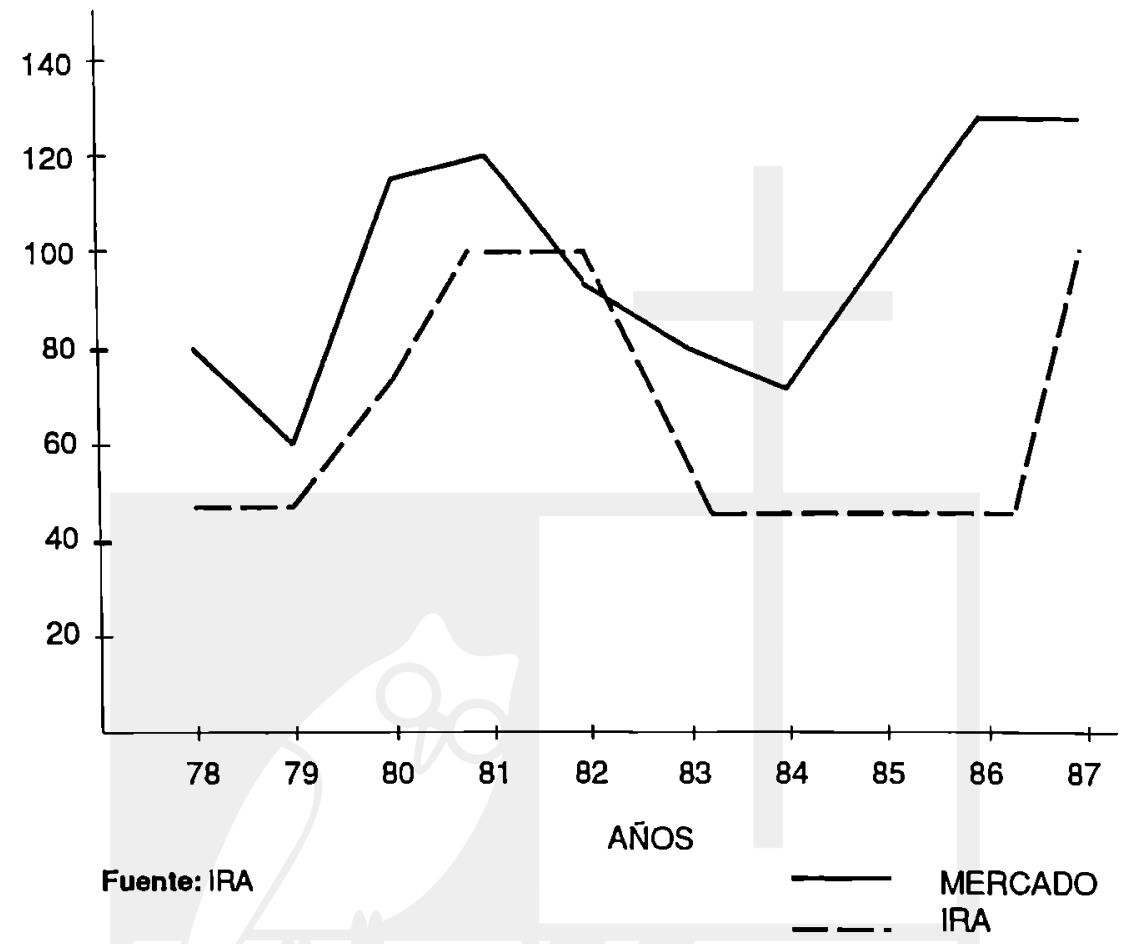

En consecuencia, la restringida respuesta de la producción interna da como resultado un exceso relativo de demanda que se traduce a la vez en presión inflacionaria de origen agricola.

La política para el subsector agricola productor de alimentos seguida por el Gobierno ha buscado atenuar estas presiones mediante las importaciones de granos. (Ver gráficos 7,8 y 9 )

Como podrá apreciarse, lo común a los tres productos durante el período de los sesenta, es la notable estabilidad de sus precios internos, pese a que la demanda ejerce una constante presión durante todo el período, como resultado de la dinámica de crecimiento impulsada por el auge del Mercado Común Centroamericano. ${ }^{15}$

Dicha estabilidad puede ser atribuida a la adecuada complementación de la insuficiente producción interna con importaciones. 
GRAFICO N 6: Precios del arroz o ro establecidos por el IRA y el mercado a nivel consumldor $1978 / 88$

๘/OOS

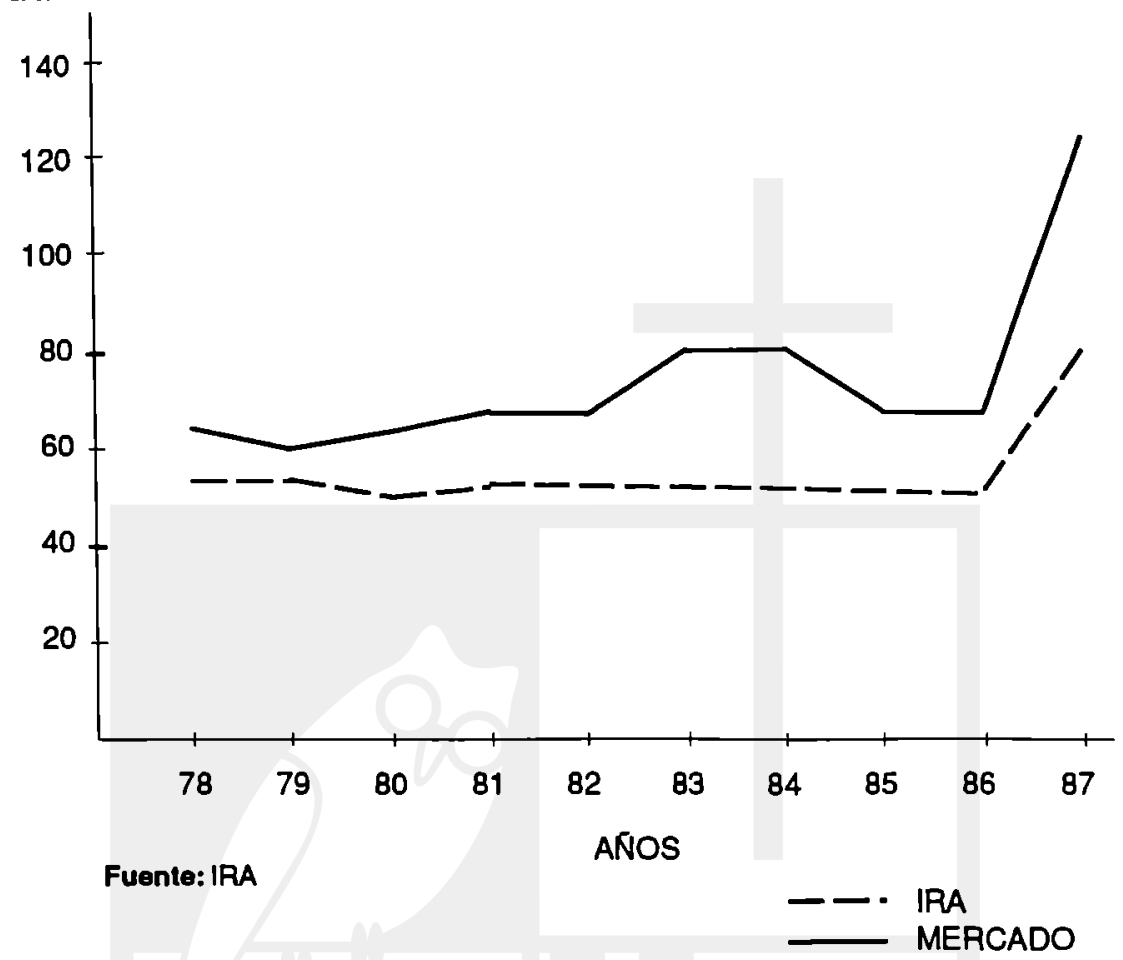

Por el contrario, la década de los setenta (finales de los sesenta en el caso del frijol y principios de los setenta en los otros dos productos) se caracteriza por la inestabilidad de los precios.

Durante este periodo, los precios de los tres granos muestran una tendencia alcista, la cual es motivada por diferentes causas. En el caso del frijol, esa tendencia es el resultado de la contracción considerable de las importaciones a partir de 1969. Para el maiz y el arroz, el fenómeno mencionado no puede ser explicado por la falta de importaciones, ya que no dejaron de realizarse en ese periodo.

En ese sentido, la estabilidad o su situación opuesta no ha dependido exclusivamente del comportamiento de las importaciones, sino también de otra serie de variables que han estado presentes.

Para la década de los sesenta también debe considerarse la influencia que, por una parte, ha jugado la menor inelasticidad que la oferta 


\section{PRODUCCION, IMPORTACIONES Y PRECIOS DEL MAIZ \\ PERIODO 1959/60 - 1986/87 1962=100}

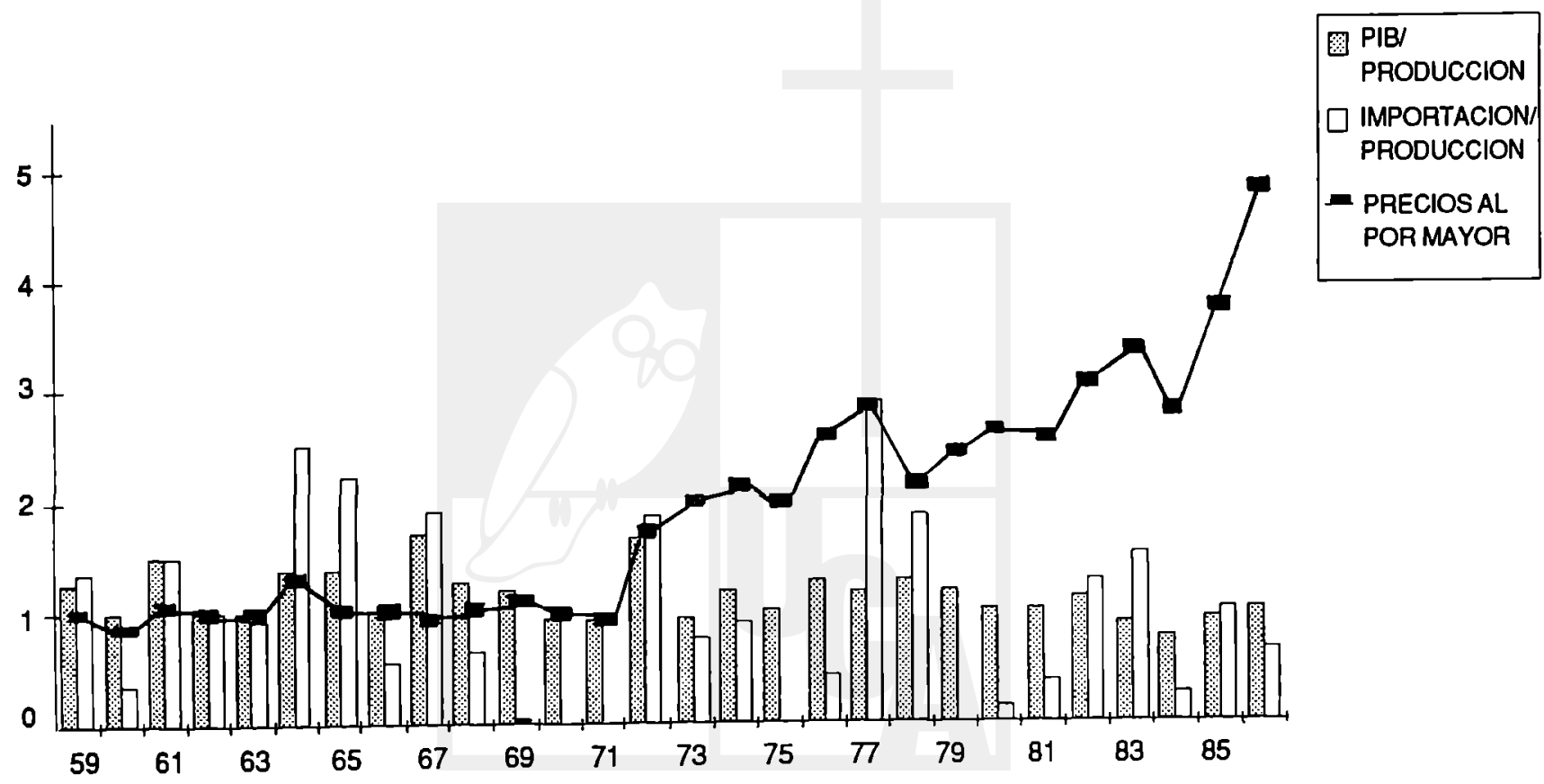

Fuente: Elaboración propia en base a procedimiento del Gráfico № 8.

$\overrightarrow{\mathrm{N}}$ 


\section{GRAFICO № 8}

\section{PRODUCCION, IMPORTACIONES Y PRECIOS DEL FRIJOL \\ PERIODO 1959/60 - 1986/87 1962=100}

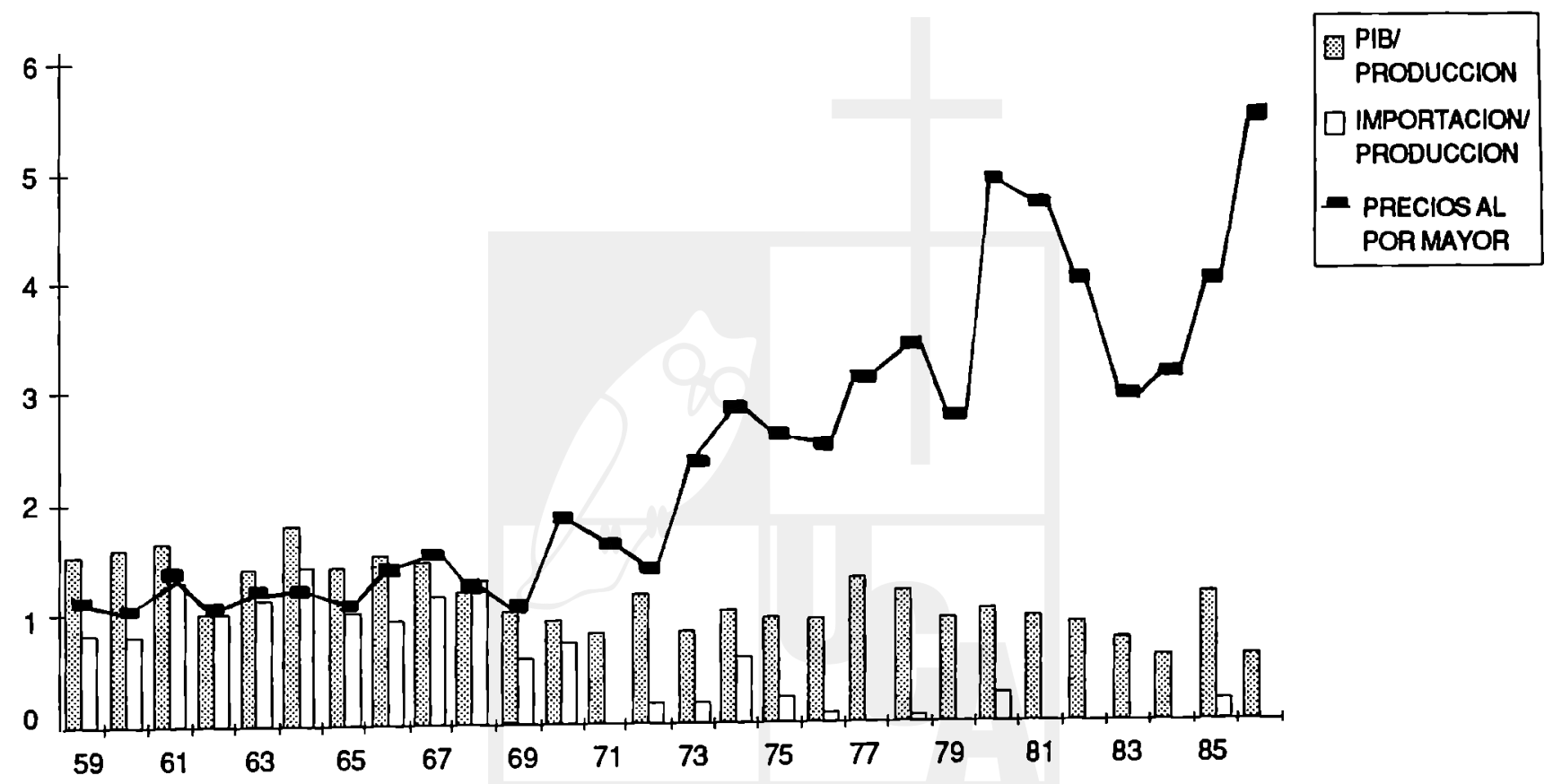

Fuente: Rivera C. "Producción de Alimentos y Desbalances Macroeconómicos" 


\section{GRAFICO № 9}

PRODUCCION, IMPORTACIONES Y PRECIOS DEL ARROZ

PERIODO 1959/60 - 1986/87 1962=100

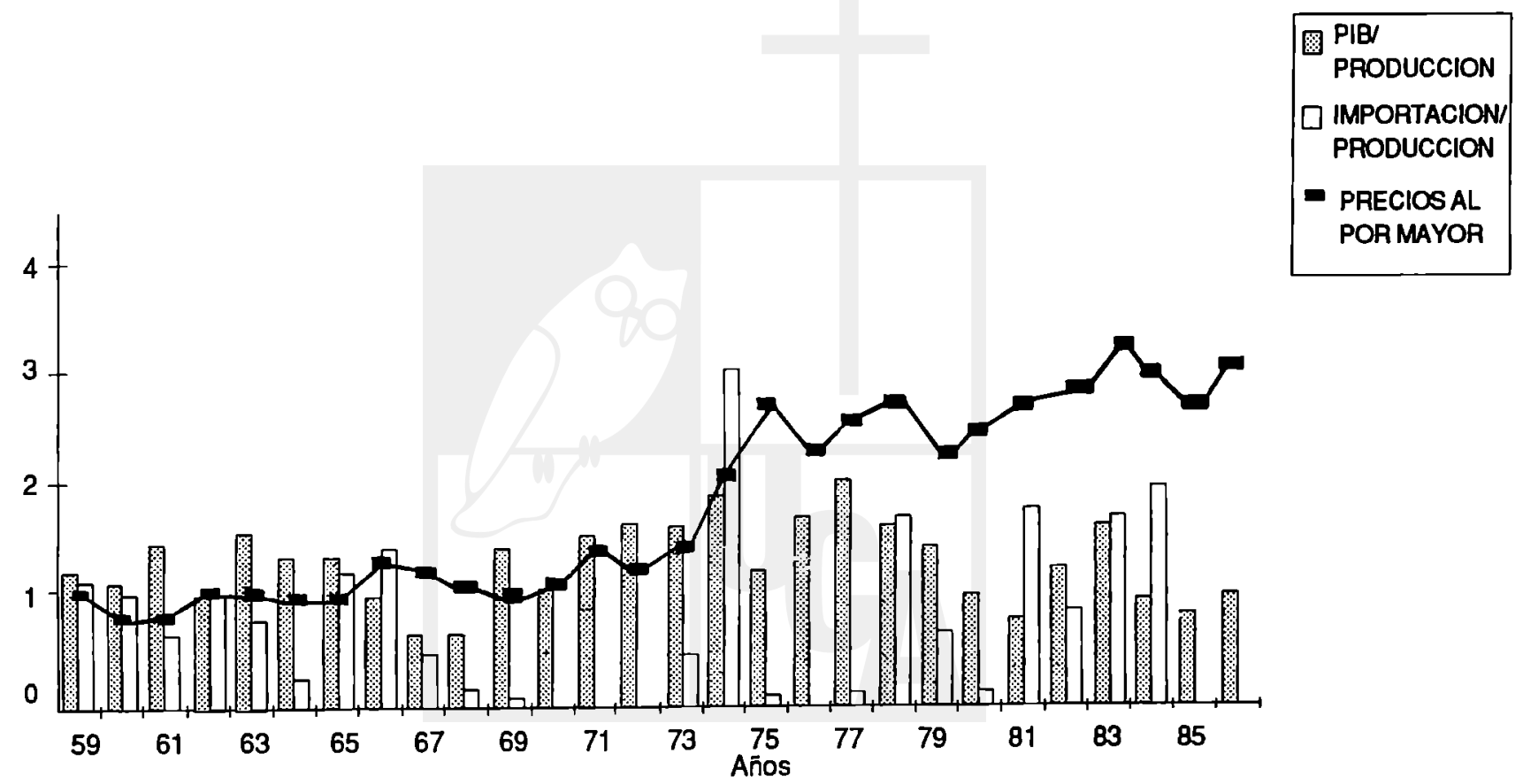

Fuente: Elaboración propia en base a procedimiento del Gráfico № 9. 
agricola mostraba; y por otra, la ausencia de presiones inflacionarias via costo de los insumos importados.

En cambio, para la década de los setenta, y la de los ochenta, las variables adicionales que explican la tendencia alcista son: Posiblemente el cierre del mercado hondure ho (en el caso específico del frijol); la sequia mundial de 1972; el incremento de los precios del petróleo en 1973, lo que impactó más significativamente sobre los precios del arroz, debido principalmente a la mayor mecanización de su producción, asi como los mayores gastos de comercialización que implica; la devaluación del tipo de cambio en 1986 y, finalmente, la reciente sequía que afectó las cosechas 1987/88, principalmente la del frijol. Por otra parte, debe tenerse presente que la oferta agricola en los setenta se tornó más inelástica que en el período precedente.

Entonces, es posible afirmar que el sector externo restringe la influencia y/o participación que puedan tener los mecanismos internos dentro de la formación del precio de los granos. En este sentido, las importaciones pasan a constituir una variable de la formación de los precios internos.

No obstante, tal mecanismo restrictivo está acotado a su vez por la acción de otros factores, unos de carácter más permanente que otros, que pueden acentuar o atenuar el resultado sobre los precios derivado exclusivamente del mencionado mecanismo.

En definitiva, el estudio de la dinámica de los precios permite identificar las variables que están presentes como determinantes de la formación del precio de los granos básicos en el país. Estos son, por el lado de la oferta: el comportamiento de la demanda y la oferta especulativa de los intermediarios, los precios oficiales del IRA, los precios internacionales de las importaciones de granos y los costos de los insumos agricolas. Por el lado de la demanda, su excesivo nivel frente al estancamiento de la oferta interna.

\section{Conclusiones y recomendaciones}

\subsection{Concluslones}

La contrastación de las hipótesis de trabajo con los resultados del estudio realizado permiten concluir lo siguiente:

- La configuración de la estructura agraria salvadorefia y la orientación de la política económica, condicionan la forma no capitalista de la producción de granos básicos.

- Precisamente, la forma en que es desarrollado el proceso de producción para cada grano en particular, determina la participación que 
cada factor tenga en su estructura de costos.

- En general, dentro de la estructura de costos de los granos, son los costos de los insumos los que tienen mayor peso, ocupando el segundo lugar los desembolsados para la contratación de fuerza de trabajo.

- El pequeno productor tiene un reducido poder de negociación del precio de venta frente a los intermediarios privados, lo que no le permite fijar un precio que cubra sus costos.

- Dentro del conjunto de intermediarios privados, la capacidad de especular está concentrada en manos de los mayoristas, quienes son los que mayor influencia ejercen sobre la oferta y los precios de mercado.

- La estructura de comercialización que presenta el mercado de granos en el pais, provoca movimientos estacionales y temporales sobre los precios, lo que genera efectos negativos, tanto para el productor directo como para el consumidor final.

- La proporción de la oferta que el IRA controla sólo es suficiente como para influir limitadamente sobre los precios de mercado, los que a la larga terminan atrayendo a los precios regulados.

- El sector externo restringe la influencia que pueden tener los mecanismos internos dentro de la formación del precio; a su vez, el papel restrictivo de las importaciones está limitado por la fuerza que adquiera la interacción del resto de mecanismos que intervienen en la formación del precio de los granos básicos.

- Las anteriores consideraciones permiten sefialar que las variables que están presentes como determinantes en la formación del precio de los granos son; por el lado de la oferta: el comportamiento de la demanda y oferta especulativa de los intermediarios, los precios internacionales de las importaciones de granos, los precios oficiales del IRA y los costos de los insumos agrícolas. Por el lado de la demanda, su excesivo nivel frente al estancamiento de la producción interna.

- Es claro, entonces, que el precio de los granos básicos es determinado esencialmente por los mecanismos del mercado y no direc ${ }^{\dagger}$ mente por las variaciones en los costos de producción.

\subsection{PIstas para una estrategla alternatlva de soluclón}

Es claro que las permanentes presiones inflacionarias originadas por el sector agrícola productor de alimentos provienen de la tendencia al estancamiento que muestra la producción interna frente a una demanda 
excesiva creciente. La base de esto se encuentra fundamentalmente en la baja productividad que caracteriza a este sector, generada por condicionantes estructurales e institucionales y por la orientación de la politica agricola.

Los resultados de la presente investigación permiten sefialar que la solución a la problemática del precio de los granos pasa necesariamente por la alteración del funcionamiento de su estructura de comercialización, ya que de ésta derivan los efectos negativos del sistema de precios de los granos para el productor directo y el consumidor final. En base a esto, se pretende en este apartado presentar algunos lineamientos generales de política económica que pueden contribuir a la solución eficaz de los problemas detectados.

-Respecto a las condiciones del proceso de producción, en primer término debe redefinirse el contenido que en la práctica presenta la asistencia técnica; es decir, no debe reducirse a meras instrucciones ocasionales sobre el uso de ciertos insumos, sino que ésta debe contemplar una revisión contínua de los resultados de la aplicación de las técnicas recomendadas. Asimismo, debe considerarse la ampliación de la asesoria técnica a un mayor número de productores.

Las medidas anteriores deben enmarcarse dentro de un programa tecnológico cuyo criterio rector sea incrementar los niveles de productividad sin agravar el problema del desempleo en el agro. Esto presupone cierto tipo de medidas tendientes a elevar no sólo la productividad por hombre; sino también la productividad por hectárea.

- En cuanto a las condiciones de financiamiento, debe redefinirse la orientación de la política seguida por las instituciones crediticias oficiales respecto al financiamiento de la producción de los pequeños productores. Esto presupone en primer término, que se incrementen significativamente los recursos para las líneas de crédito destinadas a financiar la producción de granos.

La anterior medida debe acompañarse de la puesta en acción, por parte de estas instituciones, de criterios y requisitos financieros alternativos que tomen en cuenta las limitadas condiciones económicas y de recursos que poseen los pequefios agricultores, ya que los actuales criterios y requisitos inhiben a éstos de solicitar créditos para sus cosechas.

-En lo referente a las condiciones del mercado de granos, es imprescindible actuar sobre su estructura de comercialización a fin de que sea el productor quien efectivamente se apropie del excedente generado.

Concretamente, debe promoverse la organización de los pequeños productores en cooperativas de venta administradas de manera autó- 
noma por sus asociados. Se considera que, en términos de viabilidad, esta idea es más operativa que la de un cambio en la organización del proceso productivo mediante la creación de cooperativas de producción. En primer lugar, porque esto último implicaría cambios Institucionales más profundos y, en consecuencia, mayor oposición por parte del capital agrícola. En segundo lugar, debido al obstáculo impuesto por la dispersión geográfica de las pequefias explotaciones.

Las cooperativas de venta, al conceder a los productores de granos el control de la oferta que individualmente no pueden ejercer, lograrían por una parte, un mayor poder de negociación del precio y por otra, irían paulatinamente desplazando a los intermediarios de su control sobre el mercado. En consecuencia, la venta de granos en forma cooperativa permitiria a los pequeños productores la captación del excedente, mediante la eliminación de algunos eslabones de la cadena de comercialización y la obtención de un precio que permita cubrir sus costos y un margen adicional.

La medida anterior es considerada estratégica en base a su alcance respecto a la solución del problema esencial detectado.

-Respecto al IRA, debe considerarse una readecuación administrativa y de funciones. Esta institución debe ser reorganizada para eliminar el grave problema de la burocratización, que es causa importante de la mala imagen que posee ante los agricultores.

La sola presencia del IRA implica un control del mercado por parte del Estado, ya que sus precios son, en el caso de la compra al productor directo, el precio tope que los intermediarios estarían dispuestos a pagar $y$, en el caso de la venta al consumidor, el precio mínimo al que estarian dispuestos a vender.

Por tanto, el IRA, a pesar de que sólo controla un restringido porcentaje de la oferta interna, es un organismo que regula en alguna medida el movimiento de los precios de los granos.

En este sentido, plantear la eliminación del IRA sería una medida de política económica que agravaria la inestabilidad de los precios en el mercado.

Se hace necesario además, la utilización de criterios técnicos basados en los costos de producción para establecer el precio mínimo al productor.

En relación a la participación del IRA en el mercado, debe estudiarse la forma más adecuada de relación con las cooperativas de venta, de manera que les permita imponer conjuntamente los precios de mercado a favor de los pequefios productores. 
-El criterio de la politica de importaciones debe redefinirse en el sentido de que éstas sean utilizadas como una válvula de emergencia en aquellas situaciones en que la oferta, debido a contingencias naturales, no pueda responder a la demanda interna y no como una solución permanente al déficit en la producción local. Ciertamente, esta consideración se ubica dentro de una perspectiva de largo plazo, ya que presupone un incremento de la oferta interna a través de un cambio radical en la productividad con el objeto de estrechar la brecha alimentaria. De esta manera, atacando las causas estructurales del déficit en la disponibilidad de granos, $y$, en consecuencia, redefiniendo el criterio para importar, se reducirian las presiones sobre la Balanza de Pagos provenientes de este rubro y se lograria incentivar la producción interna. Asimismo, el problema de la dependencia alimentaria se vería minimizado.

Se hace necesario recalcar que se está consciente de las implicaciones que la aplicación de las medidas propuestas acarrearian sobre el resto de la economía. Al respecto, se procede a exponer los probables escenarios.

En un primer caso, debido a que con la creación de cooperativas de venta se eliminaría la intermediación, los margenes de comercialización pasarian a manos del productor directo: de manera que si sólo se considera un traslado del excedente, el precio al consumidor se mantendría igual al de los intermediarios en la actualidad. Esta situación seria la mas favorable a los consumidores; pero deja irresuelto el principal problema de los agricultores, consistente en que el precio no garantiza la rentabilidad de sus productos.

En un segundo caso, si se espera que las cooperativas exijan, además de un precio que cubra sus costos, un margen adicional; sería probable que el precio al consumidor se elevara respecto al precio actual de mercado, lo que dependerá en gran medida de las variaciones en los costos y de los niveles de rentabilidad exigidos. Tal situación no sólo parece ser la más probable; sino la más desfavorable para los consumidores, especialmente para los sectores asalariados urbanos.

El planteamiento de soluciones en un marco donde los sectores económicos los constituyen grupos de bajos ingresos, es también un problema de elección de opciones.

Si se actúa desde el punto de vista de los agricultores, los afectados serán los asalariados.

Para el caso especifico tratado, si bien el sistema de cooperativas procuraría un abastecimiento constante a los consumidores, la eliminación de la intermediación se haria, quizás, a costa de un mayor precio. 
Ante la mencionada consecuencia, podrlan plantearse dos salidas:

En primer lugar, los sectores asalariados presionarian por mayores salarios, lo que constituiria la base de una espiral inflacionaria al traducirse los incrementos en los costos salariales a los precios de los productos manufacturados y de éstos a los costos agrícolas.

La capacidad de solucionar el problema mediante aumentos sucesivos de salarios dependerá a su vez del poder de organización de los asalariados y del poder de concesión de los capitalistas. En todo caso, atacar las presiones inflacionarias creando más inflación es una solución que no podria mantenerse por mucho tiempo.

En segundo lugar, una solución más a fondo exige un cambio en las condiciones de la oferta agrícola, lo que implica reestructuraciones institucionales que tienen como meta lograr incrementos sustanciales en la productividad de la agricultura de alimentación. Esto último se perfila como único camino para que este sector no siga constituyéndose en un límite estructural de nuestro desarrollo económico.

\section{NOTAS}

1. Ferguson, C.E. y J.P. Gould. "Teorla Mlcroeconómlca". Pág. 229.

2. Ferguson, C.E. y J.P. Gould. Ibld. Pág. 228.

3. MIPLAN. "Polltica Naclonal de Producción: Area Granos Básicos y Allmentos". Págs. 105-107.

4. Montoya, Aquiles. La necesidad teórica de la categorla subsunción indirecta del trabajo en el capital. Rev. Realidad Enero/febrero/88, p. 71.

5. Se refiere a una entrevista personal realizada como parte de la investigación presente, en agosto de 1988.

6. Fuente: IRA. Estad/stices del IRA.

7. MIPLAN. Ibld. Pág. 116.

8. Ferguson, C.E. y J.P. Gould. Ibid. Pág. 361.

8. IRA: "Politica para el Cultivo de Granos Básicos 1988-1989. Pág. 4.

10. Fuente: Entrevista a funcionarios del IRA.

11. Fogelbach Avila, F. y E.G. Vargas. "Causas Estructurales e Instltucionales que Inclden en la producción y comerclalización de los Granos Básicos en El Salvador". Pág. 134.

12. Fogelbach Avila, F. y E.G. Vargas. Ibid. Pág. 135.

13. Meléndez Méndez, J.R. "Caracteristicas Generales de la Comerclalización de Granos Básicos (Málz, Frijol, Arroz y Maiclilo) y la Participación del IRA (1970-1982)". Pág. 183.

14. Llort, Mercedes y A. Trigueros. "Productividad Agroalimentaria". Págs. 7079.

15. El procedimiento utilizado está basado en la comparación de dos coeficientes. El primero, al establecer la relación entre la producción interna total y la producción de granos (PIB/producción) da una idea de qué tanto 
esta última es capaz de suplir la demanda generada por el resto de sectores de la economía a cada nivel de PIB. El segundo coeficiente (Importación/Producción) indica el peso relativo de las importaciones de granos respecto a su producción interna. Se tomó como base la aplicación de este método al caso del frijol por Rivera Campos en "Producción de Alimentos y Desbalances Macroeconómicos".

\section{BIBLIOGRAFIA}

\section{LIBROS:}

Dada Hirezi, Héctor. Le Economla de El Salvador y la Integración Centroamerlcana 1945-1960. UCA Editores. 1985.

Ferguson, C.E. y J.P. Gould. Teorla Microeconómica. Ed. F.C.E., México. 1983.

Fitzgerald, E.V.K. "Apuntes para el Análisis de la Pequeña Economla Subdesarrollada en Transición" (L_e Transiclón Dlficll) Ed. Siglo XXI México. 1986.

Kalecki, Michal. Ensayos sobre las economlas en vlas de desarrollo. Ed. Crítica. Barcelona. 1980.

Ensayos escogldos sobre dínámica de la economla capltalista 1933-1970. Ed. F.C.E., México. 1982.

Taylor, Lance. Modelos macroeconómlcos para los palses en desarrollo. Ed. F.C.E., México, 1986.

\section{TESIS:}

Azcunaga Sánchez, Milagro del Rosario; y otros. Los Mecanlsmos de Control del Ministerlo de Economía en la estabilizaclón de preclos para productos de consumo básico en el mercado Interno. Tesis de grado. Universidad Centroamericana. Noviembre 1981.

Fogelbach Avila, Francis $\infty$ José y Evert Galeano Vargas. Causas estructurales e Inst|tuclonales que Inclden en la producción y comerclallzaclón de granos bésicos en El Salvador. Tesis de grado. Universidad Centroamericana. Noviembre de 1981.

Llort Zapata, Mercedes R. y Armando Trigueros Hernández. Productivided Agroallmentarla. Tesis de grado. Universidad Centroamericana. Marzo 1988.

Meléndez Méndez, Jorge René. Caracteristlcas generales de la comerclallzación de granos básicos (málz, irljol, arroz y malcillo) y la particlpación del IRA (1970-1982). Tesis de grado. Universidad Centroamericana. Diciembre 1984.

Novoa Flores, Edgardo José y Eleonora Gavidia de Novoa. Procesos Económlcos que Afectan a los Pequeños Productores Agrlcolas. Tesis de grado. Universidad Centroamericana. Mayo 1983.

Reyes Bonilla, Delia Lorena y Aracely Portillo Campos. Articulaclón y Funclonalidad de los Pequeños Productores Agricolas con el Slstema Capltallsta Salvadoreño. Tesis de grado. Universidad Centroamericana. Septiembre 1987. 


\section{REVISTAS:}

Briones, Carlos. "Algunas Reflexiones sobre el Funcionamiento de la Economía Salvadoreña: Complementariedades y Contradicciones". Boletin de Clenclas Económicasy Soclales. Año IX, NR 4. 1986.

Montoya, Aquiles. "La Subsunción Indirecta del Trabajo en el Capital (su Necesidad Teórica)". Realidad Económlco-Soclal. Año I, № 1. 1988.

Pleitez, William. "Reforma Agraria y Desarrollo Económico: "Un Examen Crítico de la Experiencia Salvadoreña". Boletin de Ciencias Económicas y Soclales. Año IX, N2 4. 1986.

Rivera Campos, Roberto. "La Inflación en El Salvador". Realidad EconómicoSoclal. Año I, № 1, 1988.

"Producción de Alimentos y Desbalances Macroeconómicos". Documento de Trabajo. Departamento de Economla. Universidad Centroamericana. 1988.

\section{DOCUMENTOS:}

Alvarez Solls, Francisco A. y Ricardo Stein Heinemann. Dlagnóstico de la Sequla 1987/1988 y su Impacto Económlco-soclal on El Salvador. E.D.C. consultores. Julio 1988.

DIGESTYC. Tercer Censo Naclonal Agropecuario. Dirección General de Estadistica y Censos. 1971.

IRA. Polltica para el Cultivo de Granos Báslcos 1988-1989. Documento Interno de Trabajo IRA. 1988.

Estadlsticas del IRA. Documento Interno de Trabajo IRA. Abril 1988.

Ladman, Jerry R.; y otros. Mercados Financleros Rurales de EI Salvador (Movilizaclón de Ahorros y Crédlto Agropecuarlo). USAID/El Salvador. 1986.

MAG-DGEA. Cultıo de Granos Báslcos 1986. (Varios Documentos). Ministerio de Agricultura y Ganaderla; Dirección General de Economia Agropecuaria. 1986.

MIPLAN. Pollitlca Nacional de Producción. Area de Granos Báslcos y Allmentos. Ministerio de Planificación y Coordinación del Desarrollo Económico y Social. 1986.

Rivera Campos, Roberto. "Apuntes de Macroeconomla III. Tema: Formación de Precios". Universidad Centroamericana. Ciclo 02. 1986. 